\title{
A reevaluation of the Late Jurassic dinosaur tracksite Barkhausen (Wiehengebirge, Northern Germany)
}

\author{
Christian A. Meyer ${ }^{1}\left(\mathbb{D} \cdot\right.$ Matteo Belvedere $^{2}\left(\mathbb{D} \cdot\right.$ Benjamin $^{\text {Englich }}{ }^{3} \cdot$ Martin G. Lockley $^{4}(\mathbb{C}$
}

Received: 9 February 2021 / Accepted: 22 April 2021 / Published online: 8 July 2021

(c) The Author(s) 2021

\begin{abstract}
A restudy of the Barkhausen dinosaur tracksite shows that the track-bearing surface reveals considerably more detail than previously indicated, and a new map is presented, showing the trackways of nine sauropods, traveling north, possibly as a group. These are among the smallest sauropod tracks recorded in Europe. There is also evidence of two large theropods crossing the area, one moving to the south and the other to the west. Evidence of at least three other sauropods is registered in the form of isolated manus traces that represent larger individuals. Previous interpretations inferred that sauropod trackways trended south, and therefore suggested a predator chasing its prey as in the purported but controversial attack scenario claimed for the famous Paluxy River site in Texas. Based on the present study, this scenario is no longer tenable for the Barkhausen tracksite. The description of Elephantopoides barkhausensis (Kaever and Lapparent, 1974) shows that it represents a moderately wide gauge, but small manus sauropod and can be assigned under the ichnofamily label Parabrontopodidae. E. barkhausensis as originally defined was a nomen dubium, but it has since been re-described semi-formally, without renaming, we emend the description and assigned them to the ichnotaxon Parabrontopodus barkhausensis comb. nov. These tracks could have been produced by the small sauropod dinosaur taxon Europasaurus. The problematic ichnotaxon Megalosauropus teutonicus (Kaever and Lapparent, 1974), which represents a large three-toed theropod, is assigned to the recently described ichnogenus Jurabrontes from the Late Kimmeridgian of the Swiss Jura mountains as Jurabrontes teutonicus comb. nov. Furthermore, we attribute the theropod tracks from the time equivalent Langenberg quarry to the same ichnotaxon.
\end{abstract}

Keywords Sauropod and theropod trackways $\cdot$ Jurassic $\cdot$ Kimmeridgian $\cdot$ Northern Europe $\cdot$ Palaeoenvironment

\section{Introduction}

The Barkhausen Dinosaur tracksite, discovered in 1921 (Ballerstedt 1922a, b), was first described in some detail by Friese (1972, 1979) and Kaever and Lapparent (1974), and reillustrated by Haubold $(1971,1984)$ and Thulborn (1990).

\section{Handling Editor: Mike Reich.}

Christian A. Meyer

chris.meyer@unibas.ch

1 Department of Environmental Sciences, University of Basel, Bernoullistrasse 32, 4056 Basel, Switzerland

2 Dipartimento Di Scienze Della Terra, Università Degli Studi Di Firenze, Via La Pira, 4, 50121 Florence, Italy

3 Dinosaurierpark Münchehagen, Alte Zollstraße 5, 31547 Rehburg-Loccum, Germany

4 Dinosaur Trackers Research Group, University of Colorado Denver, PO Box 173364, Denver, CO 80217-3364, USA
For a more detailed history on the discovery and geoconservation, we refer to Fischer et al. (2021). The site is open to the public and therefore represents one of the most scientifically and educationally interesting Late Jurassic tracksite destinations in Northern Europe. The site displays what we may call a sauropod-theropod track assemblage, in association with a mixed carbonate-siliciclastic facies (cf. Lockley et al. 1994a; Lockley and Meyer 2000). Kaever and Lapparent (1974) named the large prominent three-toed theropod tracks Megalosauropus teutonicus and the rounded or oval tracks Elephantopoides barkhausensis. Both these ichnospecies have proved problematical, because they were not adequately described or compared with tracks from other sites.

In May of 1998 and 1999, two of the authors (CAM and MGL) visited the site, at the invitation of the municipality of Bad Essen, with a view to remapping the site and providing an updated interpretation of the dinosaur footprints. The primary aim was to provide an interpretation of the types of dinosaurs that frequented this region, so that interpretative 
signs could be prepared for public education. This work resulted in an unpublished manuscript upon which part of the present paper is based. This manuscript also formed the basis for the explanatory panels that were subsequently mounted at the tracksite. Brief notes and a map of the site were subsequently presented by Lockley and Meyer (2000), and the Barkhausen sauropod tracks were briefly compared with Cretaceous sauropod tracks from Münchehagen (Lockley et al. 2004).

Another visit was made by the first author and BE in August 2020 and aimed at a complete drone survey of the surface and to obtain 3D models of the important sauropod and theropod tracks.

Based on different studies (Bailly et al. 2000; Jank et al. 2006; Cäsar 2012; Zuo et al. 2018) and our own observations, we compiled sufficient information on the sedimentology and litho- and chronostratigraphy of the site, to describe the ancient environment in which the dinosaurs were active.

\section{Methods}

In 1998 and 1999, we used a traditional compass and tape method to survey the tracksite. The main bedding plane surfaces was marked off in meter squares using chalk, and then mapped onto $\mathrm{cm}$ graph paper. Ropes were used to gain access to the relatively small number of tracks that were high on the surface. Latex was used to make molds of selected sauropod footprints, subsequently converted into fibreglass replicas now in the University of Colorado Museum of Natural History (UCM) as UCM 193.10-UCM 193.12 (initially the casts were labelled as CU-MWC referring to the former joint University of Colorado at Denver-Museum of Western Colorado Museum). Acetate film was used as tracing paper to record the precise configuration of selected trackways (e.g., the sauropod trackway illustrated by Lockley et al. 2004: fig. 5A). Tracings are also cataloged in this collection (see: https://fossilvertebratesandtraces.colorado.edu/ index.php/Front/FossilTracksCollection). We also obtained length-width measurements on manus and pes sauropod tracks, and recorded step (pace) stride and trackway width.

We chose the best-preserved footprints to perform photogrammetry and produced 3D models for an accurate documentation and precise measurements following the indications of Mallison and Wings (2014), Matthews et al. (2006), and Falkingham et al. (2018). Digital models were created with Metashape Pro (v 1.6.2), starting from pictures taken with an Olympus TG 6. Overall surface photographs were made with a drone (DJI Phantom 4 Pro) in 2020. The isolation of the tracks, the refined orientation, and the false-color depth maps of all models were produced in CloudCompare (v. 2.9.1). Contour lines were generated in CloudCompare (following Lallensack et al. 2020) and superimposed onto the depth maps in Adobe Illustrator. 3D meshes of the tracks and surfaces can be downloaded from https://doi. org/10.6084/m9.figshare.14447604, according to Falkingham et al. (2018). Post flight treatment of the drone pictures were made with AirMagic (1.0). Photographs of individual morphotypes were subsequently enhanced with Aurora HDR Express (Vers. 1.0.0; Filter: Landscape realistic, contrast 45, aperture-0.28). To further enhance the quality and contrast of the photographs, they were treated with preset algorhytms in Luminar (4.3.0).

\section{Geological setting}

The tracksite is situated in the Hunte valley, about $1 \mathrm{~km}$ south of the small village of Barkhausen, in an abandoned quarry on the northern flank of the Wiehen hills (the Wiehen Gebirge flexure). At this location, the Late Jurassic strata dip at approximately $55^{\circ}-60^{\circ}$ north east (Fig. 1) off towards the plain of Lower Saxony (see Kaever and Lapparent 1974; Fig. 2). The track-bearing beds have been assigned to the lower or middle Kimmeridgian (unit 3c3 of Kaever and Lapparent 1974) and occur at the top of a "shoaling upwards" sequence of limestone and shale, which was not quarried. These strata are overlain by micaceous sandstones that were quarried for building stones. The overall sequence indicates the increase in influx of terrigenous sediment to the area, at about the time that the tracks were made.

As summarized by Kaever and Lapparent (1974), the tracks are in the middle part of Kimmeridgian (Klassen $1968,2003,2006$ ) which is divided into four informal units (I-IV) that cannot be correlated precisely throughout the area. According to this scheme, the lower units (I and II) have a total thickness of $10.65 \mathrm{~m}$, contain much argillaceous, and some calcareous units, and have traces of dinosaurs in the upper units (8.1-10.25 $\mathrm{m}$ above the base of unit 1). They added that the best traces, those seen on the main surface, are in unit III, which consists of thick bedded $(30-50 \mathrm{~cm})$ sandstones (Fig. 2).

We recognized most of the units (I-IV sensu Klassen 1968) seen by Kaever and Lapparent (1974) and noted that the main track-bearing layer lies at $10.9 \mathrm{~m}$ above the base of the section, as measured independently in this study. We also recorded a second "trampled" layer at $11.25 \mathrm{~m}$ (Fig. 3). The third layer can only be seen in cross section. According to our interpretation, most of the sandstones lie above this level. According to Klassen (1968), the fourfold division of the Kimmeridgian, observed to the east of the Wiehen Hills, cannot be precisely correlated westwards. However, recent studies on the sedimentology and sequence stratigraphy indicate that the track-bearing layers are in the middle part of the Süntel-Formation which can 


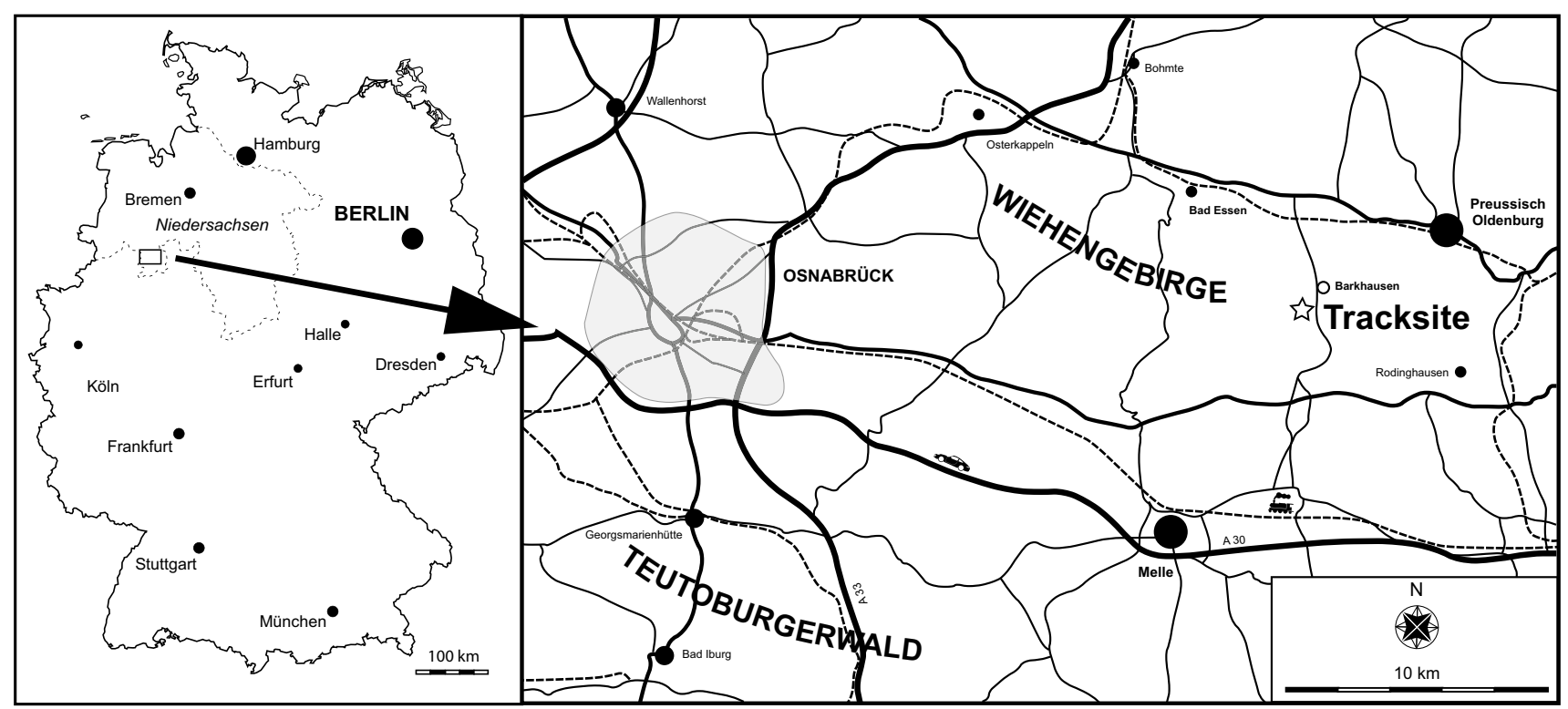

Fig. 1 Geographic location of the studied site

be attributed to the mutabilis ammonite zone (Cäsar 2012 and Fig. 2).

Kaever and Lapparent (1974) note the presence of plant fossils, attributed to Cycads, Bennetitales and Ginkgos, insect traces, large desiccation cracks, and rain drop impressions in the argillaceous sandstone lithofacies (presumably their Unit III). We noted large sub horizontal burrows on the main track-bearing surface, which we would attribute to invertebrates, of unknown affinity. Kaever and Lapparent (1974) also indicated that during the Kimmeridgian, the Barkhausen tracksite was situated on the coast of a narrow, east-west arm of the sea, known as the straits of Osnabrück. They noted however that it was not possible to say whether the tracksite represents the northern or southern arm of this narrow seaway.

Palaeoenvironmental indicators point to hyposaline-tohypersaline periods (Gramann et al. 1997). These changes in salinity are documented in brackish to limnic deposits, intercalation of marine limestones, as well as anhydrite and cellular dolomites. In the western part of the Lower Saxony basin, i.e., at the Barkhausen site, sandstones with plant remains (see above) and crumbly claystones occur. These rocks show a peculiar texture and have been called "Bröckeltonsteine" by Klüpfel (1931), Klassen (1968) and Bailly et al. (2000): literally "crumbled claystone". These sediments occur as reddish greenish clays underlying the main track level in Barkhausen (Cäsar 2012 and Fig. 3). They have been interpreted as reworked paleosols by Gramman et al. (1997) and as palaeovertisols by Bailly et al. (2000).
The main track level is a fine-grained sandstone that shows small-scale cross stratification, that is the result of a bipolar current (fig. 4 in Bailly et al. 2000).

The sedimentary rocks at the Barkhausen site document a regressive sequence that starts with fluvial sandstones with plants that are overlain by continental soils. However, the track level itself seems to have been the product of either a storm deposit or tidal currents because of the hummocky cross stratification. This would indicate that the underlying soils form a sequence boundary and the track level is the beginning of the next transgressive system tract. This was also stated by Bailly et al. (2000); however, they cite Haubold (1990a) that dinosaur track levels often occur at the end of a regressive sequence. The latter does not appear possible as during a regressive sequence, the track-bearing sequence would have been eroded away. It is therefore more probable that the track beds were preserved during the early transgressive phase after or following the end of a regressive sequence: i.e., when a transgressive system tract (TST) sediment is accumulated by coastal aggradation (e.g., Haq et al. 1987). In fact, Haubold (1990b) supported this inference when he stated that "rich fossil record is found in times of high sea level, and vice versa." In other words, aggradation helps preserve sediments that contain both body fossils and tracks.

A closer look at recent palaeogeographical maps indicates the Ringkøbing-Fünen high to the north and the Rhenish massif in the south (Lott et al. 2010 and Fig. 11), and it is most likely that the Barkhausen site represents an ancient tidal influenced delta system between these structural highs. This is supported by the palaeobotany of the underlying 


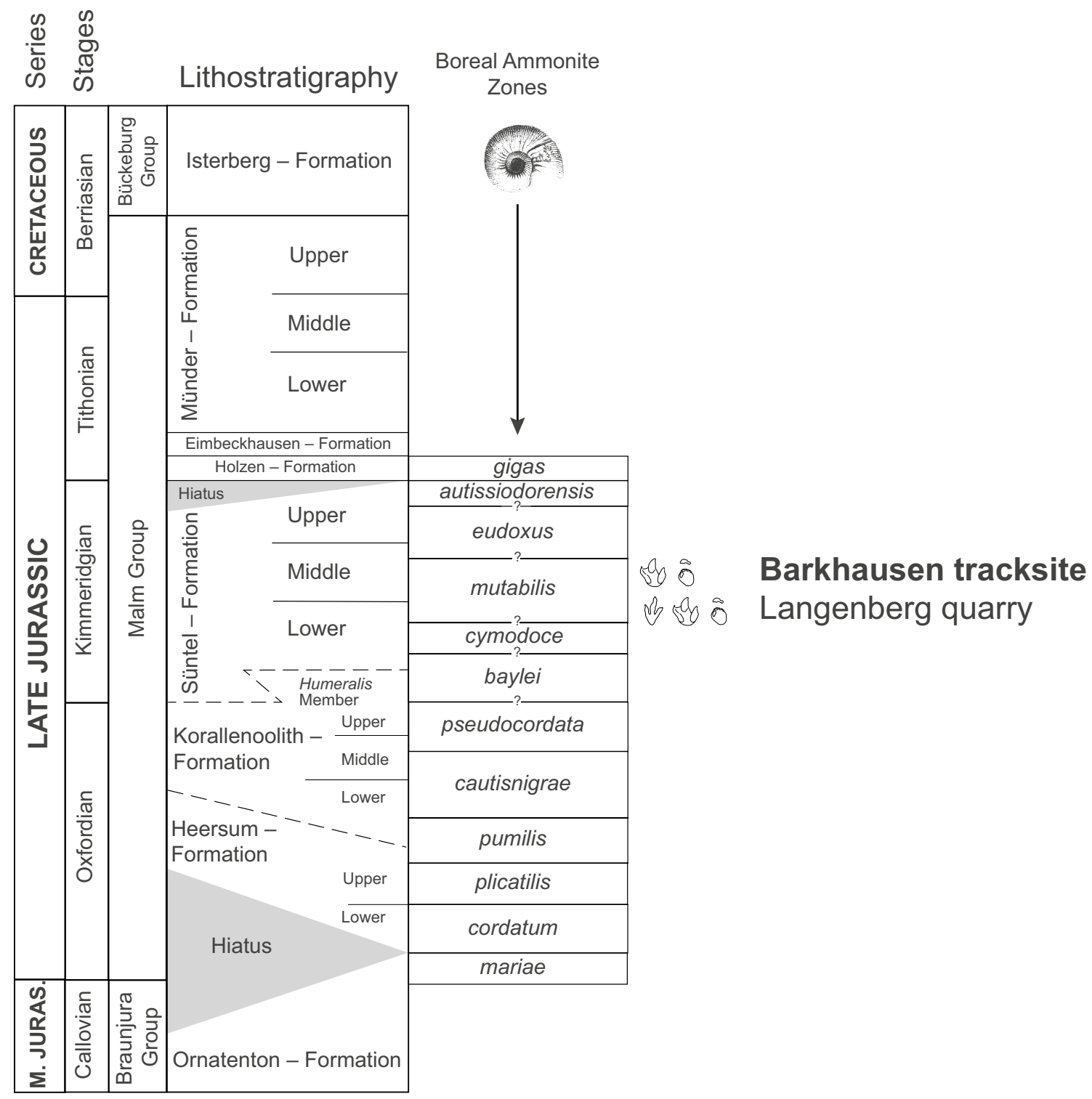

Fig. 2 Stratigraphic context of the tracksite (modified and adapted from Zou et al. 2018)

Wiehen sandstones. They were formed in a fluvial dominated delta plain (Schultka 1991). Specific plants include equisetales, osmundiacean ferns, bennetittalean cycads, and conifers such as Auracaria, Pagiophyllum, and the possible halophyte taxon Brachyphyllum. This indicates a conifer dominated vegetation associated with horsetail carpets along the riverbanks (Schultka 1991).

\section{Description of the dinosaur tracks and comparison with previous reports}

As indicated by Kaever and Lapparent (1974), the site was poorly known at the time of their study. They recognized seven trackways designated $\mathrm{a}-\mathrm{g}$, of which $\mathrm{a}-\mathrm{f}$ were attributed to sauropods heading to the south and southsoutheast. They named these sauropod trackways Elephantopoides barkhausensis. Trackway g was attributed to a large carnivore (theropod/megalosaur) also heading south (i.e., "up" after the present tectonic dip). They named this trackway Megalosauropus teutonicus. We agree with their interpretation of the tracks as those of sauropods and theropods, though the ichnotaxonomy must be amended, but in almost all other significant details, our interpretations differ to varying degrees.

For example, we recognize at least nine sauropod trackways in which several consecutive footprints are recognizable. These are numbered S1-S9 in Fig. 4, and in Table 1. All these represent animals that were progressing from the south or southwest towards the north or northeast (i.e., "down" 


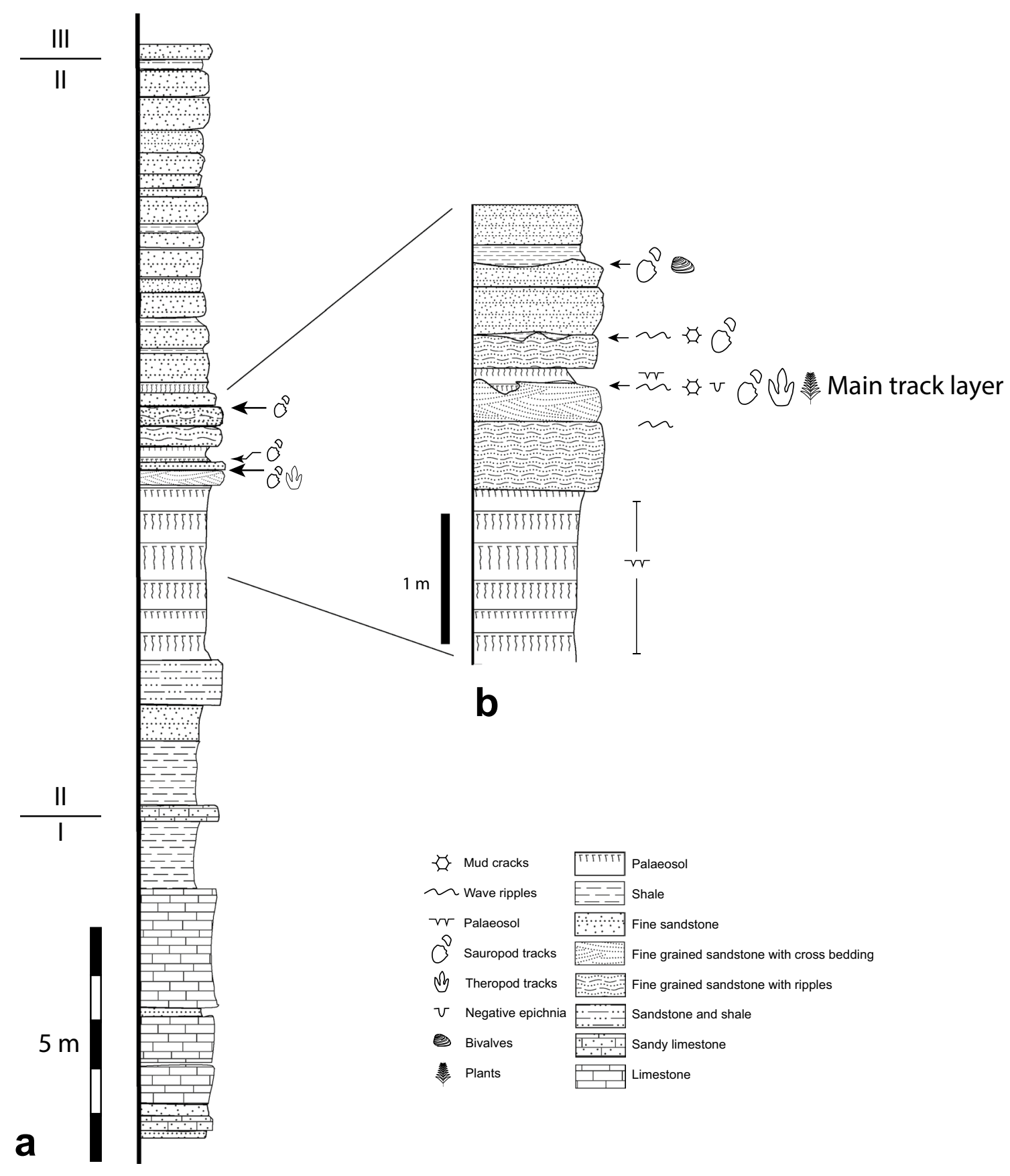

Fig. 3 Geological section of the Barkhausen tracksite. a Overall section redrawn form Bailly et al. (2000) with indication of the subunits in Roman numerals (after Klassen 1968). b Detailed section of the tracksite (logs of ML and CAM)

present tectonic dip), in exactly the opposite direction suggested by Kaever and Lapparent (1974). At least two other trackways are represented by isolated manus impressions at a higher elevation on the outcrop of the bedding plane. In addition to their erroneous interpretation of the direction in which the sauropods were heading, they suggested that most of the trackways are comprised of only pes impressions, because the hind foot overstepped the front footprint completely, or at least partially, thus explaining the oval form of the tracks as combined hind and front footprints. We do not agree with this interpretation, because we observed many manus impressions, and manus-pes pairs (e.g., Lockley et al. 2004: fig. 5A). In some cases, there was complete or partial overprinting, but in such cases, the oval outline of the pes represents the actual shape of the hind footprint, not a combination of manus and pes. 


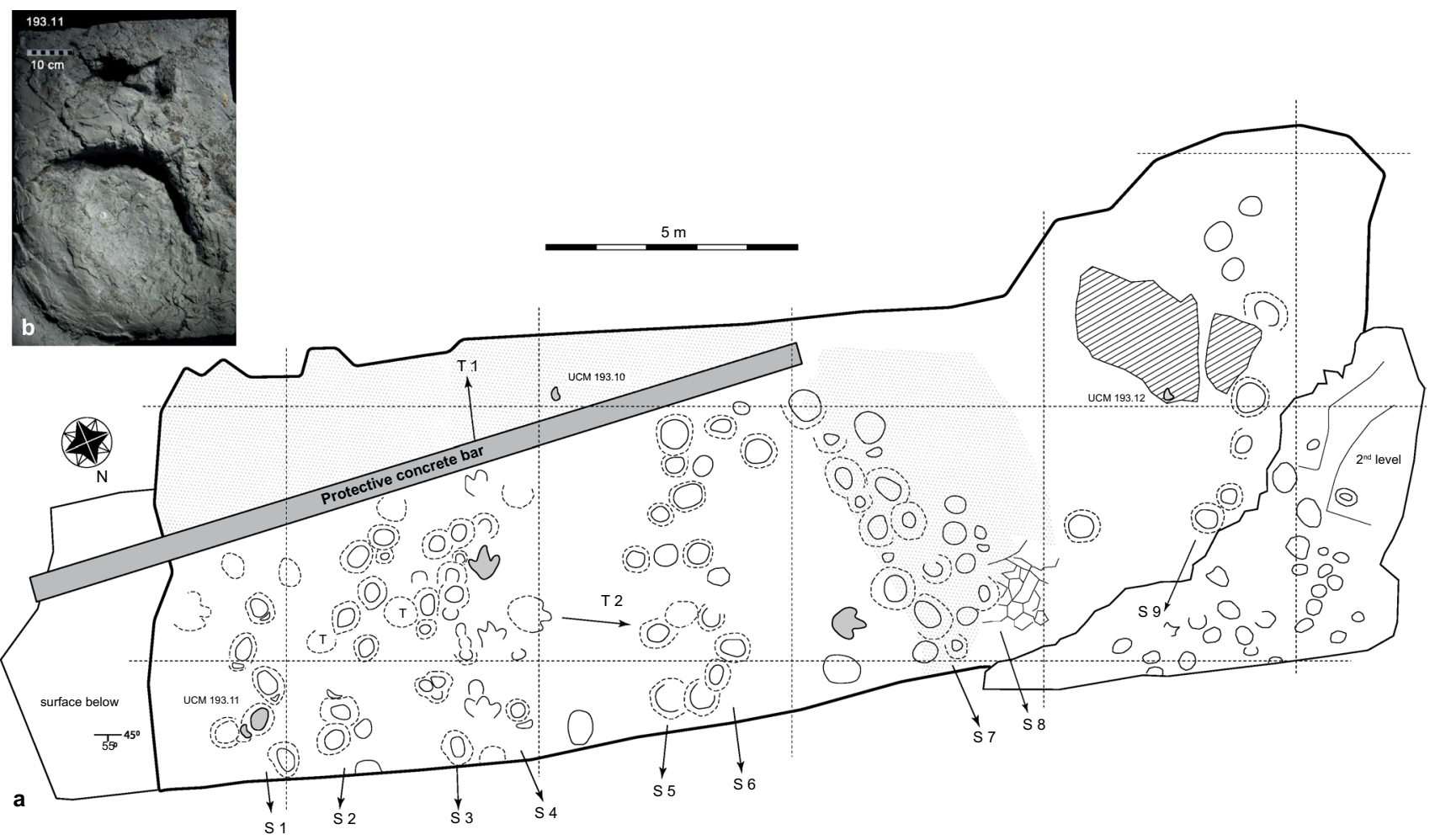

Fig. 4 a Map of the tracksite with indication of trackway numbers and tracks mentioned in the text (grey fills). b Inset shows picture of manus pes set of the cast (CO 193.11)

We also disagree with the measurements suggested by Kaever and Lapparent (1974) for the sauropod trackways. They gave the length/width measurements of footprints in trackways a-c as 50/45, 57/40 and 33/? in cm, respectively. These are equivalent to our trackways $\mathrm{S} 1-\mathrm{S} 3$, for which corresponding measurements for the pes tracks are $35 / 25$, $37 / 33$, and 30/20. Thus, it seems that the size of the tracks was significantly overestimated in most cases (on the order of $40 \%$ for the five values given for trackways S1-S3).

It is perhaps understandable that Kaever and Lapparent would have made some questionable interpretations of sauropod tracks in 1974, since most of the modern sauropod tracksite descriptions now available had not then been published. As they pointed out, very few sauropod tracksites were then known. In fact, these were the first sauropod tracks reported from Europe. This situation has changed significantly with the documentation of hundreds of trackways at many Late Jurassic sites in Europe such as Switzerland, Portugal, Spain, and France (Meyer 1990; Lockley et al. 1994b; Marty 2008; Marty et al. 2018; Belvedere et al. 2016). Late Jurassic sauropod tracksites and those from other epochs elsewhere in the world are too numerous to mention in the present study except where comparisons are necessary.

We agree with Kaever and Lapparent (1974) that trackway g (T1 in Fig. 4) represents a large theropod heading south, and we are in approximate agreement with the measurements they provide for foot size and step (pace) length. We note also, however, that four footprints in a similar but less deeply impressed trackway are visible heading towards the west (WNW). It is possible that the more distal (westerly) of these tracks (Fig. 5) was not visible at the time when Kaever and Lapparent made their study. In 1999, many of the trees around the site were felled, in preparation for a new phase of conservation and development, leading to much improved illumination of the site (Fischer et al. 2021). Indeed, at the time of our first study, conditions of illumination were excellent.

Diedrich (2011) observed 11 sauropod trackways and two theropod trackways. His interpretation of a herding of sauropods crossing the surface as well as his amended diagnosis of the two ichnotaxa (Elephantopoides and Megalosauropus) are discussed below. Lallensack et al. (2015) about Diedrich (2011) noted that "several of his conclusions are not tenable due to serious errors and insufficient evidence"; in addition, the migration hypotheses formulated there does not mention the previous works (e.g., Meyer et al. 2006; Meyer 2011). For these reasons, we refrain from further discussing the results of his study.

The surface at present comprises roughly $200 \mathrm{~m}^{2}$ of which $80 \mathrm{~m}^{2}$ are protected from erosion by a roof. Two of us 


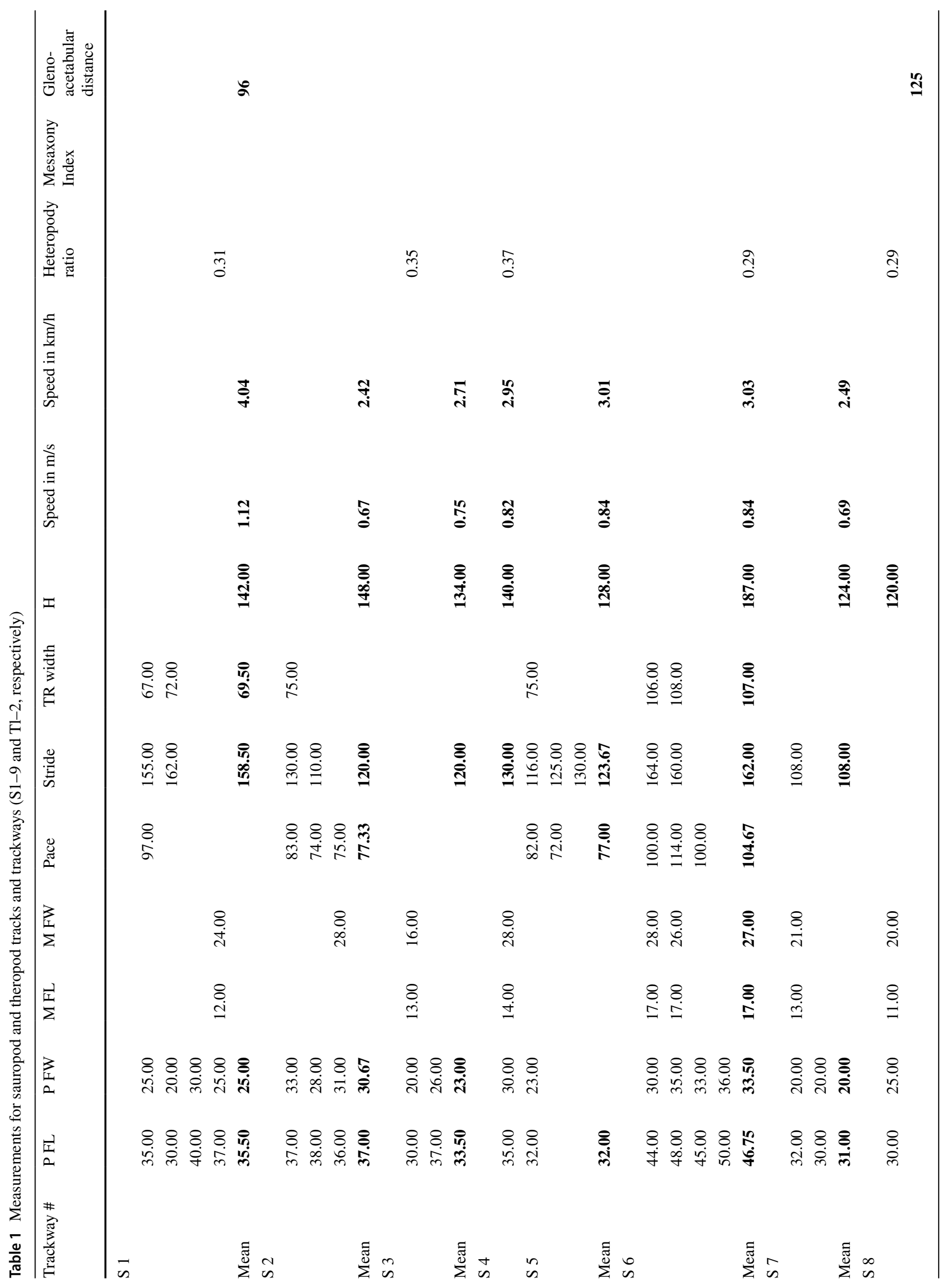




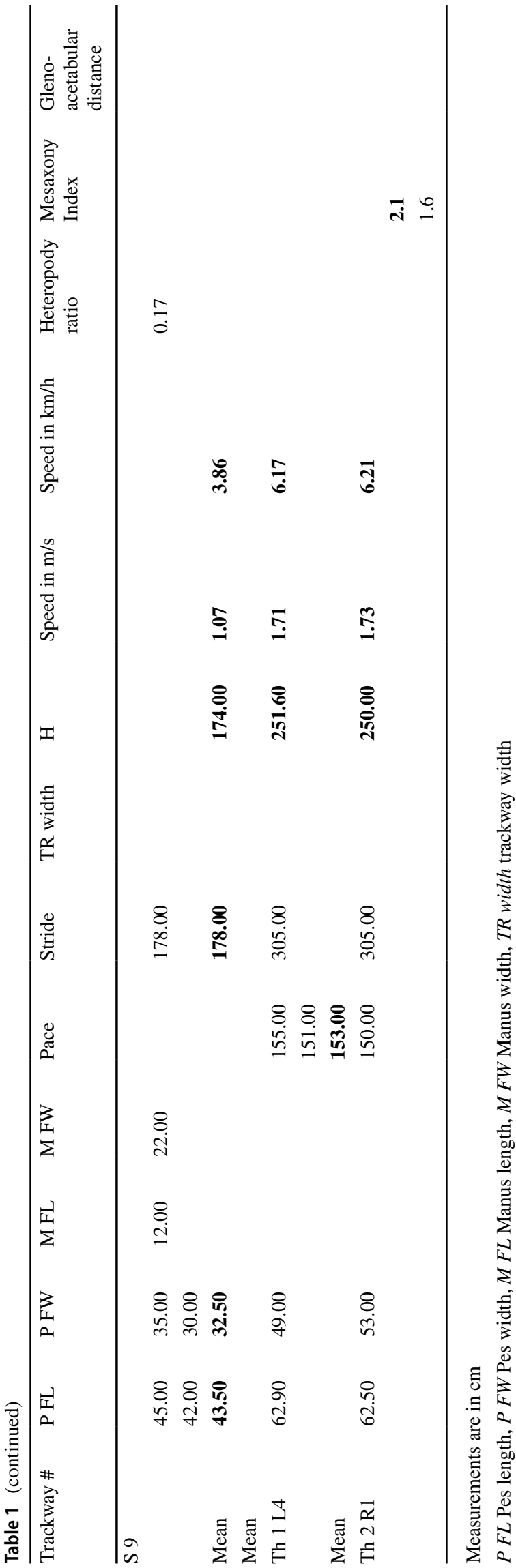

(CM and BE) have remapped the surface in summer 2020 by in situ observation and orthophotographs shot with a drone combined with 3D elevation models. On the main surface, we observed a total of 111 individual tracks of which 93 sauropod footprints in nine trackways and eight isolated tracks and nine theropod footprints in two trackways. The second track level contains 27 sauropod footprints and one possible theropod imprint. The differences between the 1999 map and the present one are minimal (Fig. 6).

Finally, we may note that the bed (unit 10) that overlies the main track-bearing surface (top of unit 9) appears to be quite heavily trampled (Figs. 3, 4). It is not possible to distinguish clear trackway segments, in this layer, and to obtain further useful footprint information, it would be necessary to clean the layer to remove a considerable accumulation of moss and other vegetation growth. Parts of this layer (unit 10) lack footprints and exhibit, by contrast, large well-developed desiccation cracks and ripple marks that trend ENE-WSW. This is in contrast to ripple marks that trend WNW-ESE on the underlying layer (unit 9). On both surfaces, the ripple marks appear to be better developed towards the west end of the exposures.

\section{Interpretation of the trackways}

Kaever and Lapparent (1974) suggested that "the carnivore was walking from north to south parallel to the other trackways left by the herbivores" and that the passage of the two types had to have been very close in time. This interpretation evidently reminded them of the famous Paluxy River site in Texas (Bird 1985), where "a large predator followed the trail of a heavy and placid herbivore. At Barkhausen also, one can reconstruct without doubt an analogous scene which took place 150 million years ago" (our translation from Kaever and Lapparent 1974: 523-524). We note here that there has been much debate as to whether the Texas interpretation is correct, because maps show that there were several theropod trackways oriented in the same direction as several sauropod trackways (Bird 1985; Farlow et al. 1989: fig. 42.1), so several theropods followed or progressed in the same direction as several sauropods. However, it has been debated whether at least one of the theropods was following or attacking one of the sauropods as to the point of a change in direction when the putative victim did (Farlow et al. 2012).

With respect to Barkhausen, Thulborn (1990) correctly noted that "Several sauropod trackways, Elephantopoides barkhausensis, extend from top to bottom: large tridactyl prints of a carnosaur, each about $56 \mathrm{~cm}$ long are headed in the opposite direction." (Thulborn 1990: 169 and 307, pl $0.13)$. No other information was given to indicate how this interpretation of the direction of sauropod trackway travel was determined. We consider however, as indicated above that it is quite correct. 


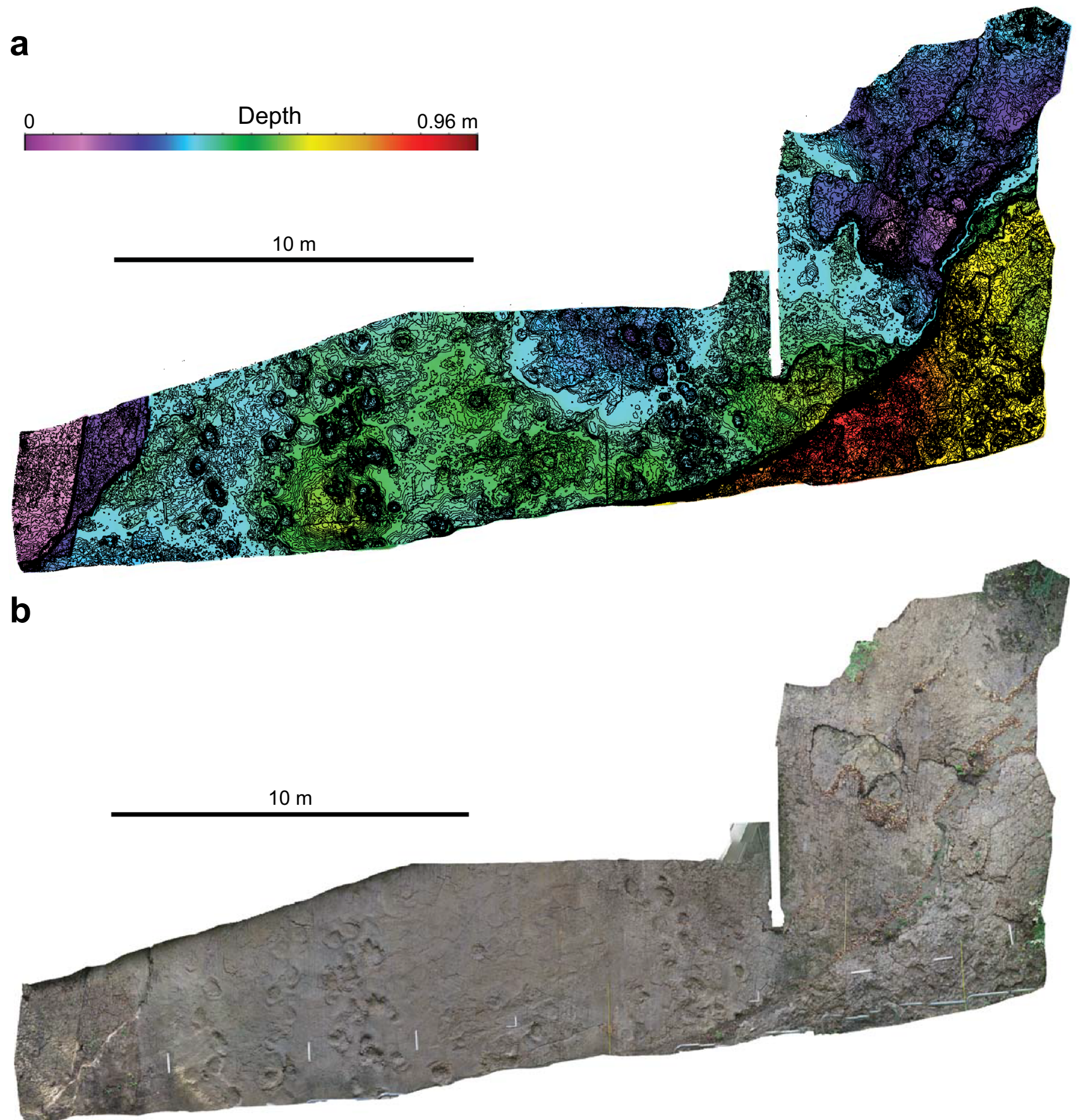

Fig. 5 3D Contour map of the site

\section{Systematic ichnology}

Descriptions of Elephantopoides barkhausensis and Megalosauropus teutonicus (Kaever and Lapparent 1974) were inadequate, as already noted by Lockley et al. (1994c). We therefore provide a revised diagnosis and description of Elephantopoides barkhausensis and discuss the status of Megalosauropus teutonicus.
Lockley et al. (1994c) suggested that, Elephantopoides barkhausensis, although on their list of "undiagnostic ichnites", may nevertheless "be of sauropod affinity". However, it was not absolutely clear, from published illustrations (Friese 1972, 1979; Kaever and Lapparent 1974) that it was not attributable to another large dinosaur. It was then also not clear that manus and pes tracks had been clearly differentiated, or anterior-posterior orientation (direction 
a
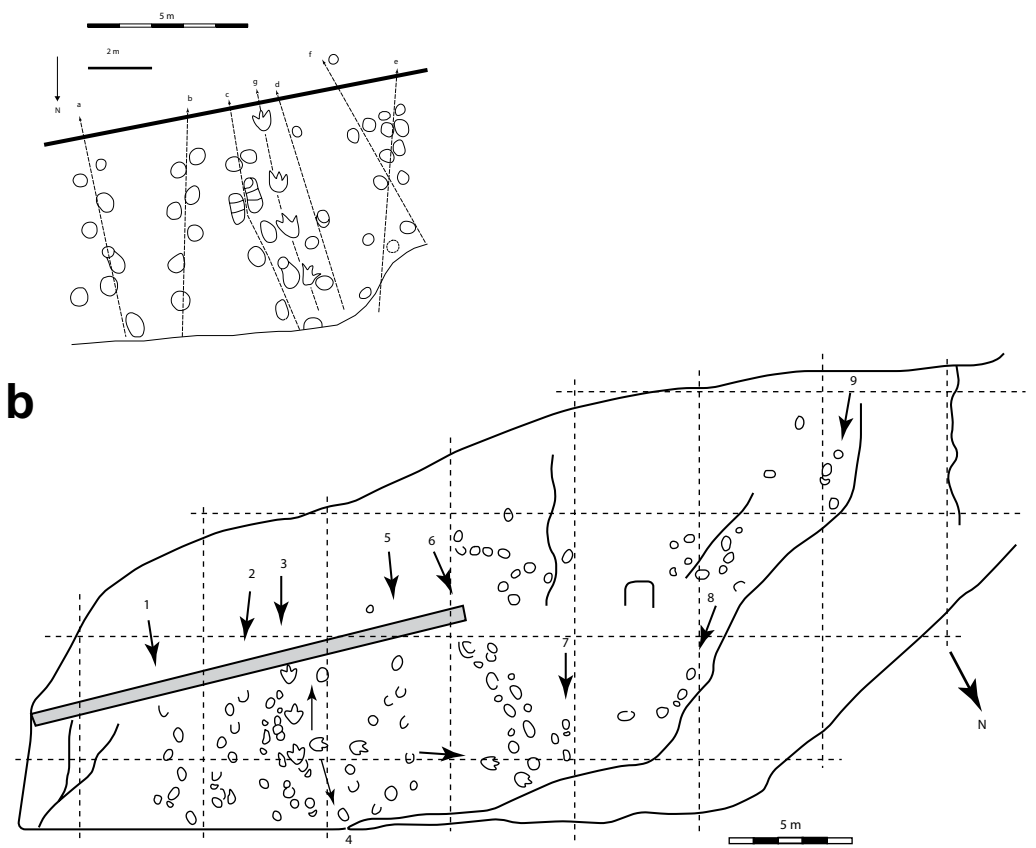

b

C

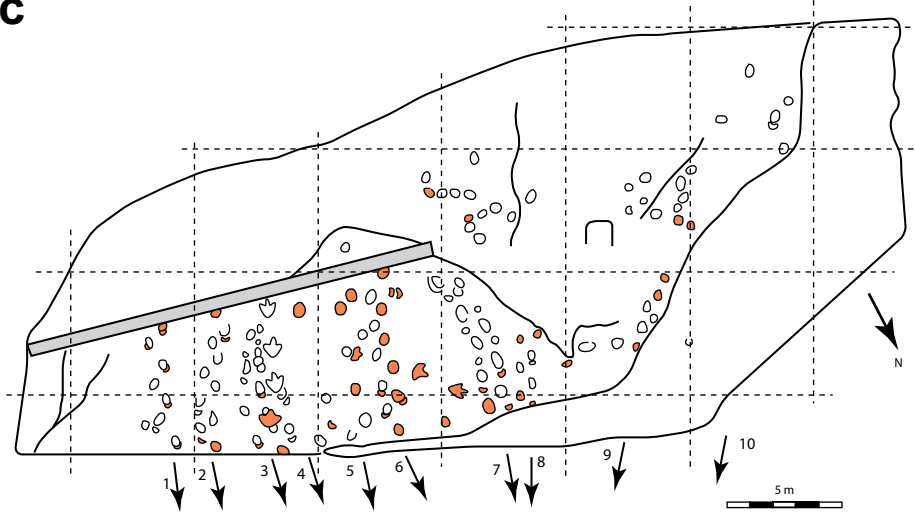

d

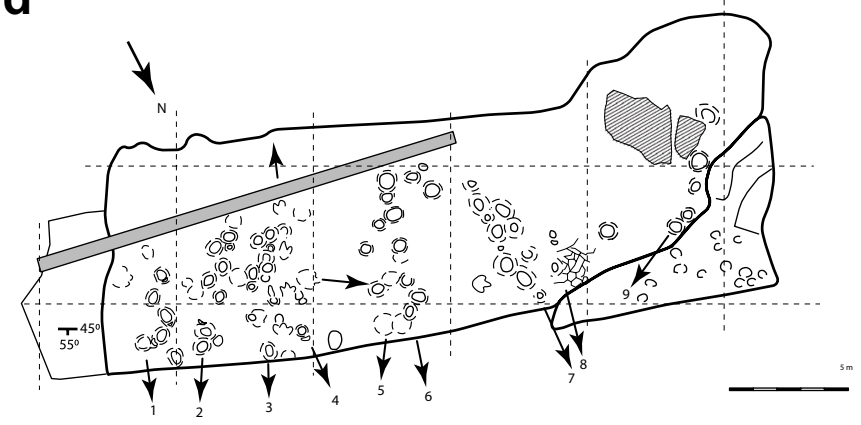

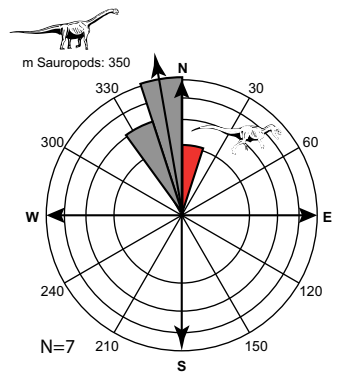
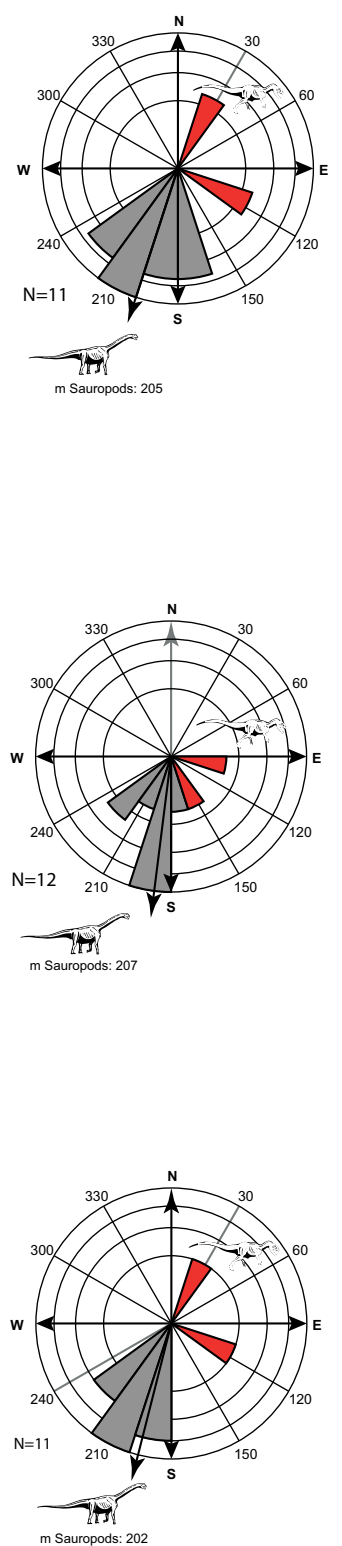

Fig. 6 Comparison of the different published maps of the Barkhausen site and traveling directions of dinosaurs: a Kaever and Lapparent 1974; b Explanatory panel at the site from Lockley et al. (2002 unpublished manuscript: compare in part with Lockley and Meyer
2000: fig. 7.9); c Diedrich 2011, tracks in color are those we did not recognize in our map; $\mathbf{d}$ this paper. Red in directional pie slices are for theropods, gray for sauropods. $N$ number of measurements, $m$ mean vector in degrees 
of travel) determined, although Klassen (in Friese 1979) pointed out the orientation error, consistent with the map presented by Lockley and Meyer (2000: fig. 7.9) and the scale trackway diagram of Lockley et al. (2004), both showing manus and pes and trackway orientations. However, this report did not discuss sauropod ichnotaxonomy as it pertained to the Barkhausen site. It is also not clear from the descriptions given by Kaever and Lapparent (1974), which of the six trackways a-f) was regarded as the holotype. For these reasons, it was suggested that the ichnospecies might be considered a nomen dubium, as then described (Lockley et al. 1994c; Lockley and Meyer 2000). The present study confirms that these are indeed sauropod tracks, but this determination is based on reinterpretations of details of track morphology, including gauge and heteropody, that depart considerably from those presented previously. Notably, since 1974 , it has been necessary to establish the correct orientation of the trackways, a reorientation of $180^{\circ}$ (Klassen in Friese 1979; Lockley and Meyer 2000), the recognition of clear manus traces, and their small size in some segments of certain trackways, the enlargement of the sample, and the acquisition of a larger set of reliable measurements than previously available. Hence, it is necessary to give a better ichnotaxonomic description of Elephantopoides barkhausensis.

Nomenclatural acts The electronic edition of this article conforms to the requirements of the amended International Code of Zoological Nomenclature, and hence, the new names contained herein are available under that Code from the electronic edition of this article. This published work and the nomenclatural acts it contains have been registered in ZooBank, the online registration system for the ICZN. The ZooBank LSIDs (Life Science Identifiers) can be resolved and the associated information viewed through any standard web browser by appending the LSID to the prefix "http:// zoobank.org/".

The LSID for this publication are: urn:lsid:zoobank. org:act:80CE46AB-3E75-4321-8FDE-3F59108F2914 (Parabrontopodus barkhausensis) and urn:lsid:zoobank. org:act:4EAF83BD-C917-4B2E-9A75-2CA0E61C467F (Jurabrontes teutonicus).

The electronic edition of this work was published in a journal with an ISSN, and has been archived and is available from the different digital repositories, e.g., PubMed Central, LOCKSS.

\section{Sauropod tracks}

Preamble. As noted by Lockley and Meyer (2000: 159), "the name Elephantpoides is inappropriate, because there is clearly no evidence for elephants in the Jurassic. Such a name may confuse lay persons..." These authors in fact used the ichnogenus names in inverted commas as "Elephantopoides" (Lockley and Meyer: fig. 7.8). Unfortunately, the ICZN code does not allow ichnotaxonomic names to be suppressed, simply because they are inappropriate or misleading, only if they are also undiagnostic, or named in contravention of rules pertaining to documentation of type material, type localities, and other fundamental attributes. In the 1990s, it was appropriate to label E. barkhausensis as an undiagnostic nomen dubium. However, subsequent studies have shown the tracks to be diagnostic examples of sauropod tracks. A first step to such improved understanding is to re-describe and re-illustrate inadequately described tracks, as has been done in subsequent publications (Lockley and Meyer 2000; Lockley et al. 2004; Diedrich 2011).

In re-illustrating the tracks, Lockley and Meyer (2000: fig. 7.9) clearly showed that trackway $\mathrm{S} 1$, is the most diagnostic, and includes both manus and pes tracks, also shown by Lockley et al. 2004: fig. 5A). Diedrich (2011) followed these examples in designating trackway S1 as the holotype. Kaever and Lapparent (1974) had not originally designated a holotype.

Such improved descriptions 'salvage' E. barkhausensis from a nomen dubium status and allow for comparison with other well-described sauropod ichnites. For example, Lockley et al. (2004: 267) stated that "much smaller manus (greater heteropody) found in sauropods from the late Jurassic Barkhausen site (Kaever and Lapparent 1974; Lockley and Meyer 2000)." This suggests a relationship with small manus sauropod tracks such as Parabrontopodus mcintoshi (Lockley et al. 1994c) which has defined has having two diagnostic characteristics: narrow gauge and small manus (strong heteropody).

\section{Ichnofamily Parabrontopodidae Apesteguia, 2005}

Ichnogenus Parabrontopodus Lockley et al., 1994c

Type ichnospecies. Parabrontopodus mcintoshi Lockley et al., 1994c.

Emended diagnosis. Narrow sauropod trackway of mediumto-large size (footprint length about 50-90 cm), characterized by no space between trackway mid-line and inside margin of pes tracks. Pes footprint longer than wide with long axis rotated outward. Pes claw impressions corresponding to digits I, II, and III show strong outward rotation. Manus tracks semicircular and small in comparison with pes tracks (i.e., pronounced heteropody) (Lockley et al. 1994c).

Description. As in Lockley et al. 1994c.

Parabrontopodus barkhausensis (Kaever and Lapparent, 1974) comb. nov.

Figures 4, 7, 8 


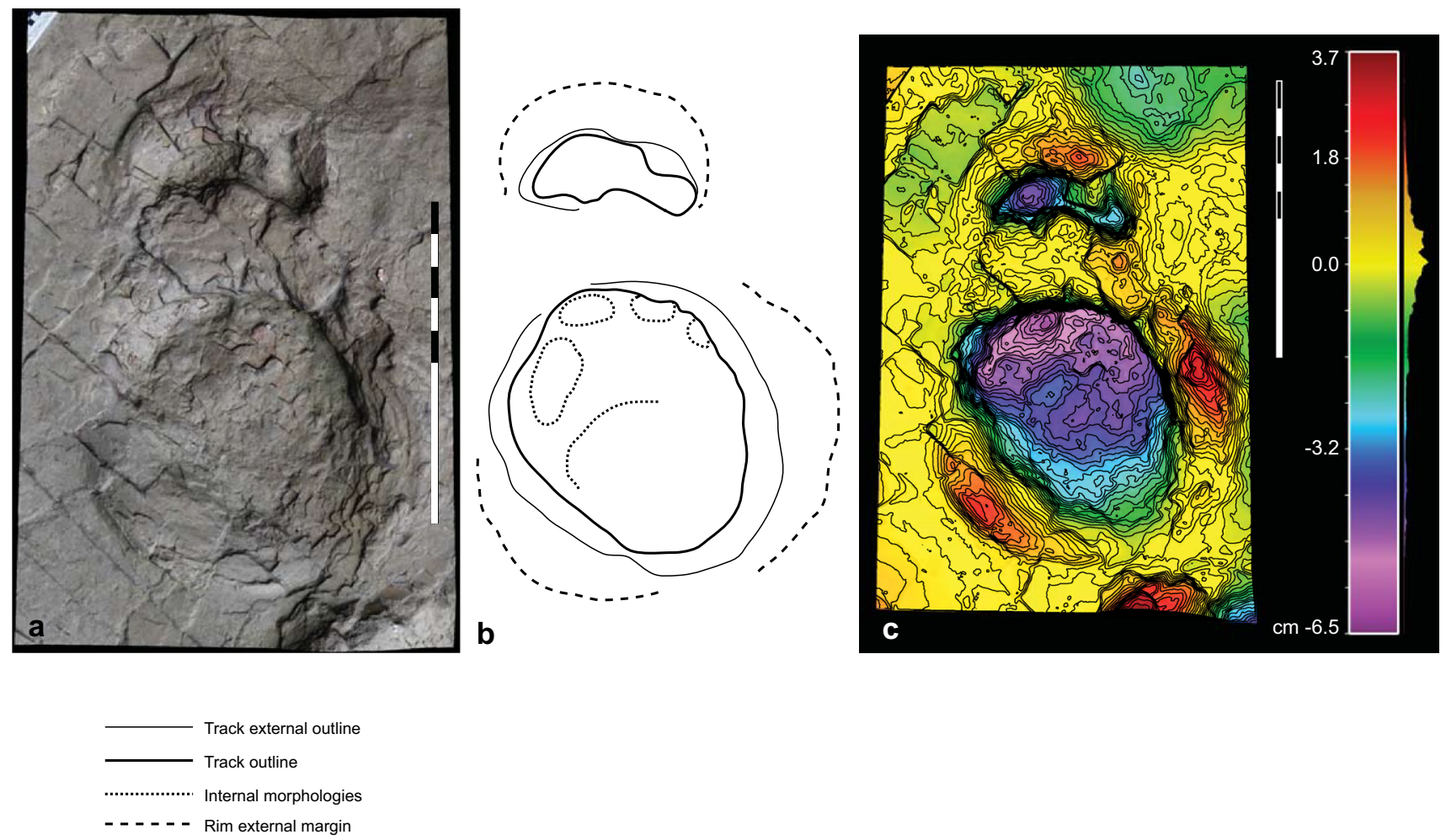

Fig. 7 Sauropod manus and pes set of the type specimen in trackway S1 corresponds to the "hard copy" replica UCM 193.11: a rectified orthofotograph. b Outline drawing. c False color and contour map (Line spacing $2 \mathrm{~mm}$ )

Diagnosis. As for ichnogenus.

Synonymy. Shortened version.

*1974 Elephantopoides barkhausensis Kaever and Lapparent. 1984 Elephantopoides barkhausensis-Haubold. 1990 Elephantopoides barkhausensis - Thulborn. 1994 Elephantopoides barkhausensis_-Lockley, Farlow and Meyer. 2000 Elephantopoides barkhausensis_Lockley and Meyer.

2011 Elephantopoides barkhausensis_-Diedrich.

2014 Elephantopoides barkhausenensis [sic!]—Rothe.

2015 Elephantopoides barkhausensis-Lallensack.

Type species. Elephantopoides barkhausensis Kaever and Lapparent, 1974.

Holotype. Trackway herein designated as number S1 (Fig. 8). No holotype designated by Kaever and Lapparent (1974), but implied/selected in a series of steps as noted above (Lockley and Meyer 2000; Lockley et al. 2004; Diedrich 2011): see replica of manus pes set UCM 193.11 from Trackway S1 in Fig. 4.

Topotypes/paratypes. Trackways S 2-5 and 7-9 (Fig. 4) from type locality.
Type locality. Barkhausen, Germany.

Type horizon. Middle Süntel Formation, Middle Kimmeridgian.

Diagnosis (emended). Trackway of sauropod, with pes trace much larger than manus trace. Pes trace oval, manus tracks semicircular and small in comparison with pes tracks (i.e., pronounced heteropody). Pes footprint longer than wide with long axis positively rotated. Pes with shallow digit impressions. Space between inner margins of pes traces approximately equivalent to one pes width.

Description. Trackway of a narrow-medium sauropod with strong heteropody (pes considerably larger than manus). Pes oval averaging about $36 \mathrm{~cm}$ long (range 30-47 cm: holotype $35.5 \mathrm{~cm}$ ) without recognizable claw impressions. Pes width averaging about $27 \mathrm{~cm}$ (range 20-33.5 cm: holotype $33.5 \mathrm{~cm}$ ). Four digits can be seen in the holotype (see Fig. 7). Manus averaging about $13 \mathrm{~cm}$ long (range 11-17 cm: holotype $12 \mathrm{~cm}$ ) and $23 \mathrm{~cm}$ wide (range 16-28 cm: holotype $24 \mathrm{~cm}$ ) in examples with well-preserved outlines. Step (pace) ranging from 74 to $114 \mathrm{~cm}$ and stride ranging from 110 to $164 \mathrm{~cm}$. The manus is positively rotated (outward) relative to the pes (between $25^{\circ}$ and $35^{\circ}$ ). External trackway width (measured from outside of pes) ranging from 67 to 


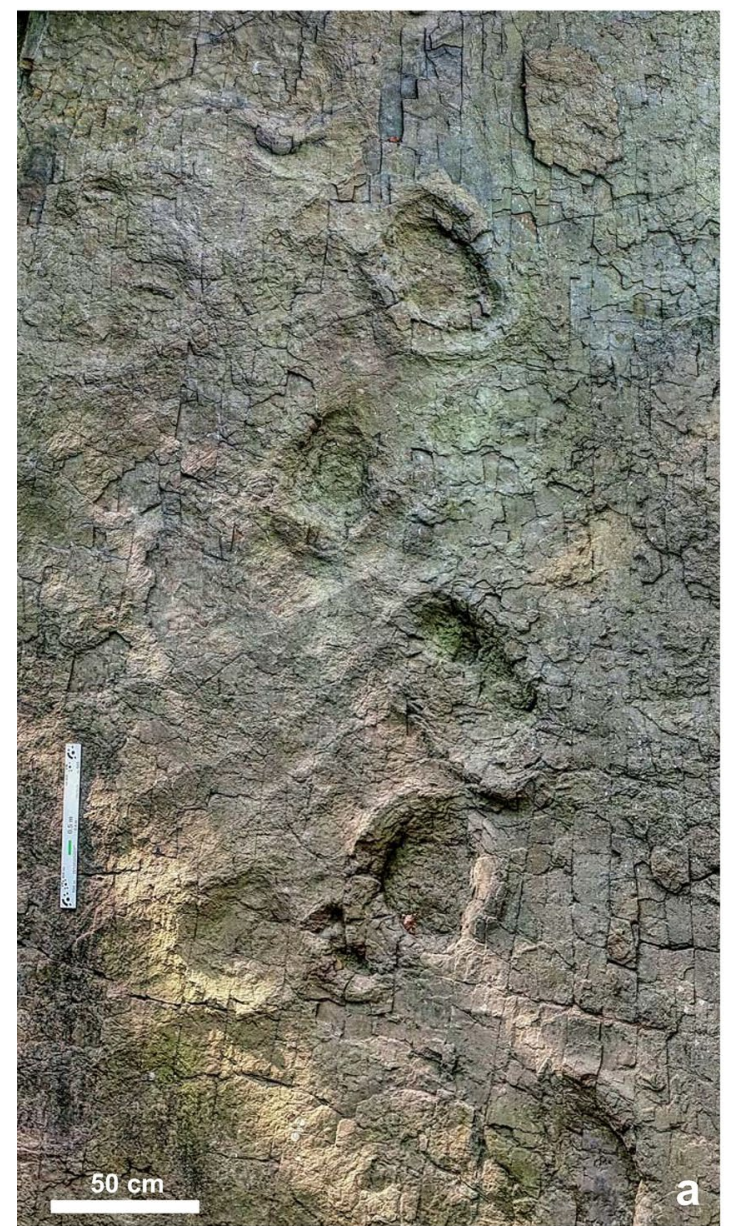

Fig. 8 Rectified orthofotograph (a) and height map of sauropod trackway 1 (S1) attributed to Parabrontopodus (b). Trackway 1 (S1) is considered as the holotype (see text). The most complete right manus

$108 \mathrm{~cm}$; internal trackway width (measured from inside of pes) from about 15-30 cm (cf. Lockley et al. 2004: fig. 5A). One trackway (S6) shows a slight curvature to right and a placement of right manus closer to the mid-line. The preservation grade of the tracks and trackways (e.g., Marchetti et al. 2019) is 1.5 .

Discussion. Elephantopoides barkhausensis occupies a special place in the history of sauropod track research in Europe, as the first sauropod tracks described and named. It is also notable that the name Elephantopoides inappropriately implies an elephant trackmaker. To confuse the issue, the trivial name has been misspelled as barkhausenensis (e.g., Rothe 2014). As suggested above, this invited labelling the ichnotaxon as a nomen dubium, because it was not shown to be diagnostic when originally defined. Thus, as unequivocal sauropod ichnotaxa were subsequently described, different sauropod trackway morphotypes were available for comparison: notably Parabrontopodus defined
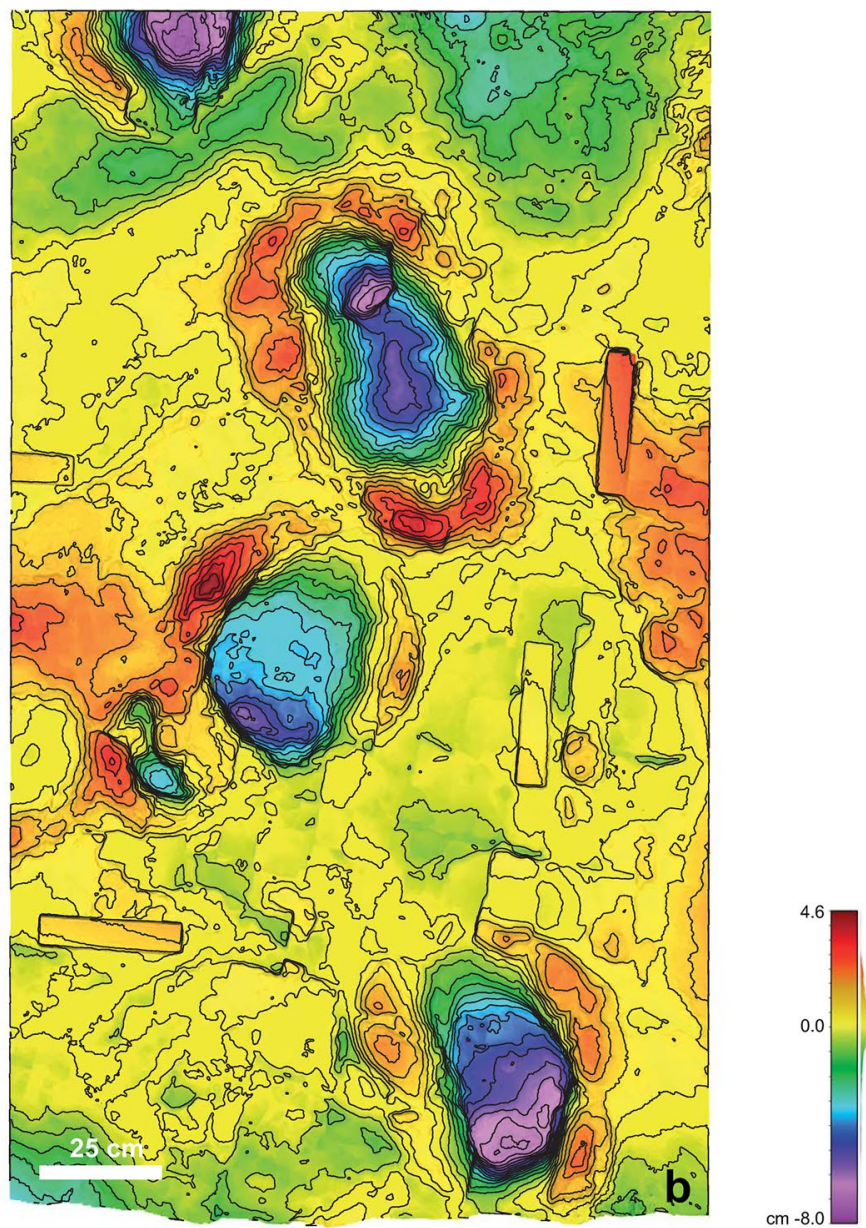

pes was molded and preserved as UCM 193.11 during the 1999 study (Contour line spacing $5 \mathrm{~mm}$ )

on the basis of a narrow gauge, small manus morphotype from the Late Jurassic (Lockley et al. 1994c).

Other named sauropod tracks from Europe include Rotundichnus muenchehagensis (Hendricks 1981; Fischer 1988; Thies 1998; Lockley et al. 2004) from the basal Cretaceous of Germany, which is clearly wide gauge but with a relatively large manus in contrast to the relatively small manus morphology of $P$. barkhausensis. No other ichnospecies have been named from the Late Jurassic of Europe, although tracks in Portugal and Switzerland have been compared, at the ichnogenus level with Brontopodus and Parabrontopodus (Lockley et al. 1994c).

As indicated in the description, and accompanying data, P. barkhausensis trackways represent sauropods of small-tomoderate size (Table 1). These size measurements are about $30 \%$ smaller, on average, than those suggested by Kaever and Lapparent (1974). Indeed, the trackways (S5 and S7) with the smallest footprints are very similar in dimensions to the small sauropod trackways previously reported from 
Western Europe, in the Late Jurassic (Kimmeridgian) of Portugal, which has a footprint length of $30 \mathrm{~cm}$ and a footprint width of $25 \mathrm{~cm}$ (Lockley and Santos 1993).

However, from the Late Jurassic of northern Switzerland, a group of 8 subparallel tiny sauropod trackways has been reported (Belvedere et al. 2016). The tracks are very small (mean PL: $11.6 \mathrm{~cm}$; PW: $7.8 \mathrm{~cm}$; ML: $4.4 \mathrm{~cm}$, MW: $7.6 \mathrm{~cm}$; small heteropody) and well preserved (dI-IV, dI-II claws, manus ungual).

Any claims that trackway S5 or S7 are Europe's smallest sauropod trackways must be considered cautiously, because the preservation of these trackways is not quite as good as those in Switzerland and Portugal. In comparison with a group of six trackways attributed to "juveniles" at another Late Jurassic (Portlandian) site in Portugal (Lockley et al. 1994b) where the mean footprint length is $42 \mathrm{~cm}$ and width $28 \mathrm{~cm}(N=6)$. The Barkhausen tracks $(N=9)$ are $14 \%$ shorter and $4 \%$ narrower, respectively, in terms of average pes length and width. Thus, the Barkhausen tracks can be considered small in comparison to those from other known European sites.

To the best of our knowledge, no one has suggested applying the name Elephantopoides barkhausensis to sauropod tracks from any localities other than Barkhausen, even though the type material discussed here has been the subject of much attention. We continue this precedent and note that the original description of the tracks prevents detailed comparisons with other sauropod ichnites, especially for ichnotaxonomic purposes. However, since the tracks have subsequently been adequately described, they can be compared with reliably established ichnotaxa, which since 1994 have been categorized according to gauge (narrow or wide) and heteropody (small or large manus). Although the Barkhausen tracks lack pes claw impressions, this is common in many sauropod tracks. However, trackways suggest an animal that had very small front feet relative to its hind footprints (high heteropody, like Parabrontopodidae: sensu Apesteguia, 2005). Such trackway configurations are seen in Breviparopus taghbaloutensis (Dutuit and Ouazzou 1980) from the Late Jurassic of Morocco (Belvedere 2008; Haddoumi et al. 2010; Marty et al. 2010) and Parabrontopodus mcintoshi (Lockley et al 1994c; Belvedere et al. 2008) from the Late Jurassic of Colorado. Both these two forms are narrow gauge. Unnamed tracks from the Late Jurassic of Portugal and Utah (Lockley et al. 1994a, c; Barnes and Lockley 1994) also show this pronounced heteropody, but are not narrow gauge. It is possible therefore that $P$. barkhausensis, like the tracks from Portugal and Utah, represents a small manus but wide gauge trackmaker.

The gauge variability shown in different sauropod track morphotypes from the Swiss Late Jurassic tracksites (Marty et al. 2010) and the Late Cretaceous of Bolivia (Meyer et al. 2018,2021 ) casts doubt on the use of this parameter as an ichnotaxonomical proxy, as suggested by Lockley et al. (1994c). The ichnotaxonomic separation of the ichnotaxon Brontopodus from Parabrontopodus based on the trackway gauge only is in our view only to be suggested with caution and needs support from other criteria most notably heteropody; stated another way large versus small manus measures of heteropody are more directly reflective of trackmaker morphology than trackway gauges which may reflect variations in gait and substrate. These polarities in sauropod gauge and heteropody have been much discussed since first proposed in the 1990s (Farlow 1992; Lockley et al. 1994a, b, c, d) and have generally been supported by theoretical and experimental studies (Wilson and Carrano 1999; Carrano and Wilson 2001; Henderson 2006).

If subsequent studies support the division of sauropod trackway types into small manus/wide gauge, as well as small manus/narrow gauge, it is possible that $P$. barkhausensis could be regarded as the first named representative of the former category. Here, we should note that we recorded three well preserved, isolated manus tracks which are not associated with the nine numbered trackways identified in Fig. 4. Two of these are impressions, one of which was found at the extreme west end of the site, just off the map. The second (UCM 193.10), preserved at the east end of the site above the wall which protects the best trackways, was replicated. The third track (UCM 193.12) from the center of the site is preserved as a raised feature and appears to be the residue of a compacted layer that was impressed onto the main track-bearing surface when the sauropod foot compacted part of the overlying layer. Raised sauropod tracks have been reported from the Late Jurassic of Utah by (Barnes and Lockley 1994).

It is interesting to note that the isolated manus tracks (S10-S12) are significantly larger than those recorded in the trackways (S1-S9), revealing an average length of $24.5 \mathrm{~cm}$ and width of $28.5 \mathrm{~cm}$ in comparison with values of 13.1 and 23.3 (see Table 1). Given that these measurements indicate manus traces $87 \%$ longer and $22 \%$ wider, on average, than those we recorded, in the trackways, we can either infer that they represent a different species or morphotype with a longer manus, or that the manus in most trackways is shortened significantly by the influence of the pes registering behind it (see Fig. 8). In trackway S6, however, manus tracks are situated far enough away from the pes tracks to suggest that such distortion was not a significant factor. Nonetheless, larger manus tracks with distinctive sauropod outlines are sporadically preserved in the main track bed without corresponding pes tracks. It is now known that isolated sauropod manus tracks, and manus-dominated or manus-only trackways are quite common in the ichnological record (Lockley et al. 1994d).

If we sum up the discussions presented above, we attribute the sauropod tracks from Barkhausen to the ichnofamily 
Parabrontopodidae. The naming of Elephantopoides predates the erection of the ichnogenus Parabrontopodus, and it was poorly understood until a series of revisions were undertaken. These revisions demonstrated that: (a) Kaever and Lapparent (1974), have not designated a holotype, (b) they did not recognize the manus tracks, (c) they incorrectly interpreted the orientation of the trackways (i.e., the direction of trackmaker progression), and (d) based on the original study and descriptions of Elephantopoides, this ichnogenus had already been declared a nomen dubium prior to this study, thereby inviting the detailed revised description given here.

Based on the presence of nine trackways at Barkhausen, that are all oriented in much the same direction, it is possible to suggest that the P. barkhausensis trackmaker was gregarious. Not all trackways are sufficiently well preserved to demonstrate that only one ichnospecies was present, however, at most sites where multiple parallel trackways occur the morphology of individual trackways is very similar, and the size range is often similar also (Lockley et al. 1994c). Conversely, there are no sets of parallel to subparallel sauropod trackways which have been interpreted as representing different species, even if they have been interpreted as representing different age groups. The Barkhausen site appears to be no exception.

Using the standard formula for estimating hip height $(=4 \mathrm{FL})$, it varies in the different trackways between 124 and $187 \mathrm{~cm}$ and the gleno-acetabular distance ranges from 96 to $125 \mathrm{~cm}$. These estimates indicate most probably small or juvenile individuals. The proportions of the coeval sauropod taxon Europasaurus from the Kimmeridigan Langenberg quarry have a trunk length that ranges from $30 \mathrm{~cm}$ in immature to $210 \mathrm{~cm}$ in mature specimens and a hip height of $20 \mathrm{~cm}$ in immature to $180 \mathrm{~cm}$ in adult specimens. Although these measurements fit well in the size range indicated by the tracks and trackways, we can only speculate that these were left by this contemporary taxon. This is because the appendicular elements such as feet and hands are only poorly known (Carballido and Sanders 2014).

\section{Theropod tracks}

Preamble. The theropod tracks from Barkhausen have a complicated and problematic ichnotaxonomic history, due to confusing use of the ichnogenus labels Megalosauripus and Megalosauropus (with an 'i' and an 'o', respectively) when first defined (Lessertisseur 1955, and Colbert and Merrilees 1967, respectively). The Barkhausen tracks were first described and named as Megalosauropus teutonicus (Kaever and Lapparent 1974). However, Lockley and Meyer (2000) pointed out: (a) that the name Megalosauripus (spelled with an 'i') had previously (Lessertisseur 1955) been coined for other theropod tetradactyl tracks from a different (Cretaceous) stratigraphic unit and site in Germany, and ostensibly also for Late Jurassic tracks (named Eutynichnium) from Portugal, and (b) the Barkhausen tracks were quite different from the type of Megalosauropus (spelled with an 'o') from Australia (Colbert and Merrilees 1967). Thus, the Barkhausen tracks were provisionally relabelled Megalosauripus teutonicus (spelled with an 'i'). This proposition also discussed by (Lockley 2000a) was controversial, challenged by Thulborn (2001) and mentioned by Diedrich (2011) as a questionable interpretation of the ICZN. However, because the type of Megalosauripus was never relocated and restudied, and because the ichnogenus label Megalosauripus (with an 'i') was widely adopted for Late Jurassic theropod tracks, as by Razzolini et al. (2017), there may not be universal agreement on the ichnotaxonomic status of Megalosauripus, (although Megalosauropus with an 'o' is restricted to the Australian type).

Regarding the Barkhausen tracks, Lockley and Meyer (2000) also demonstrated such basic features as the 1.18 $L / W$ ratio was $25 \%$ greater and more theropod-like than the $L / W$ ratio reported by Kaever and Lapparent (1974). Thus, in the original paper, the latter authors provided an inadequate description of the theropod tracks. This leaves open the need for a revision, which has been spurred by the recent discovery of other Late Jurassic theropod tracks that are more like those from Barkhausen than either Megalosauripus or Megalosauropus. Specifically, we infer that the Barkhausen tracks closely resemble the Swiss ichnospecies Jurabrontes curtedulensis described by Marty et al. (2018), who also discussed the similarity. Belvedere et al. $(2016,2019)$ also supported the similarities with Jurabrontes and preliminarily suggested a taxonomic revision of the German tracks. Given this similarity to Jurabrontes and the lack of convincing similarity to either Megalosauripus or Megalosauropus, it is appropriate to assign the Barkhausen tracks to Jurabrontes. This raises the question of whether to retain the trivial ichnospecies name 'teutonicus' under the new combination Jurabontes teutonicus nov. comb. or simply regard it as an example of J. curtedulensis. The former 'historical' option honors the formal ichnological intention of Kaever and Lapparent (1974) without declaring M. teutonicus a nomen dubium. It also allows a description of the differences between the Barkhausen, the Switzerland morphotypes, which have also been mentioned by Marty et al. (2018) and discussed also in Belvedere et al. (2019).

Ichnofamily Eubrontidae Lull, 1904

Ichnogenus Jurabrontes Marty et al., 2017

Type ichnospecies. Jurabrontes curtedulensis Marty et al., 2017. 
Emended diagnosis. Giant tridactyl tracks; longer than wide; digits II-III-IV with a clear phalangeal pad 2-3-4 configuration; peculiar and isolated position of the proximal pad PIII1 of dIII; broad sub-triangular, pointed claw marks present on the tips of all three digits II-III-IV; narrow and slightly asymmetric interdigital divarication angles (II^III < III^IV); small anterior triangle and weak mesaxony; asymmetrical heel region; broad and massive digits with a blunt aspect; lack of a hallux impression (Marty et al. 2017).

Description. As in Marty et al., 2017.

Jurabrontes teutonicus (Kaever and Lapparent, 1974) comb. nov.

Figures 9, 10

*1974 Megalosauropus teutonicus Kaever and Lapparent. 2000 Megalosauripus teutonicus_-Lockley et al.

2011 Megalosauripus teutonicus-Diedrich.

2017 Megalosauripus teutonicus_-Marty et al.

Type material. All the type specimens of Kaever and Lapparent (1974). Two tridactyl trackways from the Barkhausen Quarry. One trackway (T1) is oriented south the other (T2) shows an NW trend. Their overall morphology and robustness indicate a megatheropod trackmaker. Trackway 1 consists of four consecutive footprints which are deeply impressed in the sequence L1, R1, L2, R2. Trackway 2 consists of five footprints but only one is showing a tridactyl outline (Figs. 9, 10), and the others are very shallow and difficult to see with the naked eye. We think that T2 was originally made on a higher level and represents underprints only, despite the rather well-preserved last visible imprint

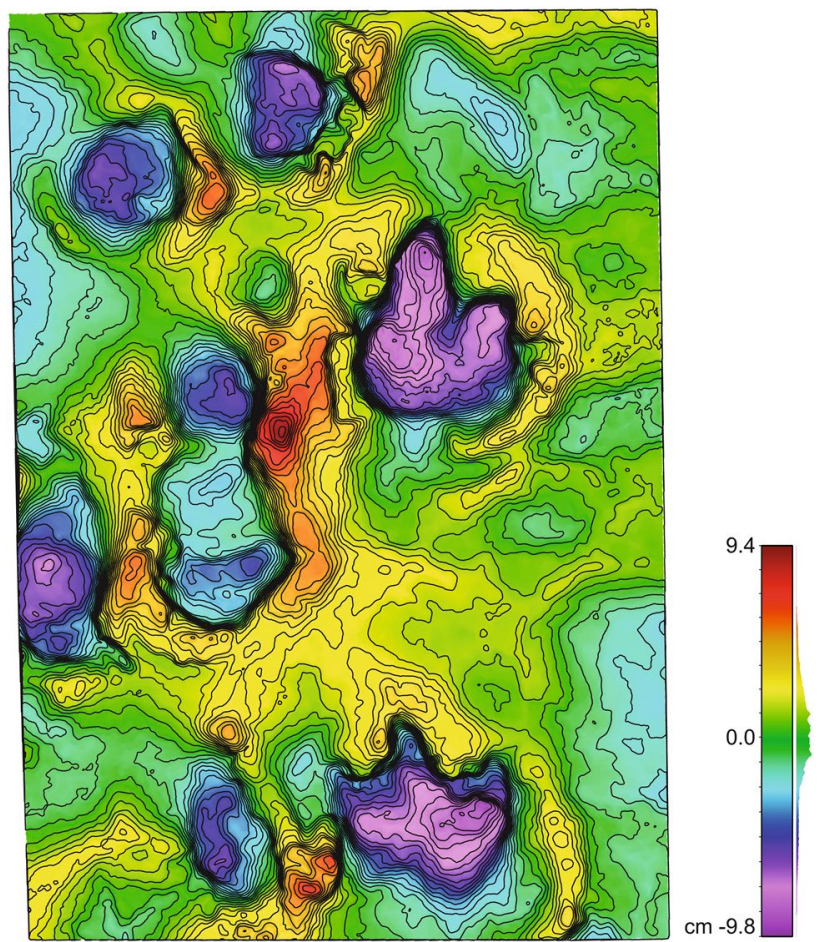

$25 \mathrm{~cm}$

Fig. 10 False color and contour map of theropod tracks of T1 (contour line spacing $5 \mathrm{~mm}$ )

(Fig. 9). However, it might also be the result of differences in the water content of the substrate.

Diagnosis (emended). Giant tridactyl track, longer than wide (L/W > 1.00). Digit traces wide and blunt. Digital pad traces
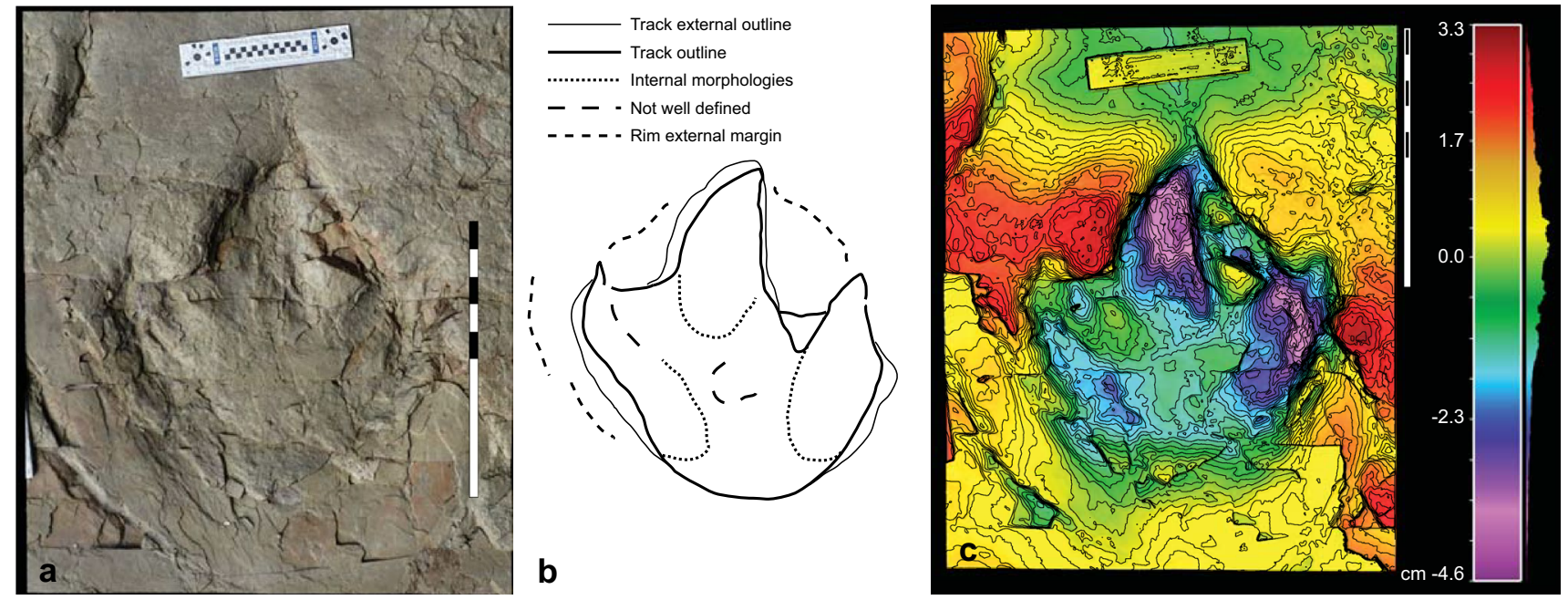

Fig. 9 Outline drawing, photograph, and height map of left footprint (L1) of Jurabrontes teutonicus comb. nov. from trackway 2 (T2). a Rectified orthofotograph; b outline drawing; $\mathbf{c}$ false-color and contour map (line spacing $2 \mathrm{~mm}$ ) 
indistinct, but distal claw marks discernable. Anterior triangle L/W ratio 0.40. Hallux traces absent. Trackway narrow, pes rotation minimal.

Description. Giant tridactyl track, longer than wide (FL: $62.5 \mathrm{~cm}$; FW: $53 \mathrm{~cm}$ : L/W 1.18), slightly asymmetric interdigital divarication angles $\left(\mathrm{II}^{\wedge} \mathrm{III}<\mathrm{III}{ }^{\wedge} \mathrm{IV}\right)$, rounded symmetrical heel region; digits are blunt; sometimes, they appear to be pointed, relatively broad and with distinguishable claw marks. Digit IV is the longest, followed by digit III and digit II; digit III is bent towards the inside of the footprint: i.e., towards the trackway mid-line; digit II impressions are generally deeper than those of digit IV; digital pad impressions are uncommon, very shallow and occur in the distal part of digit III and, in T1, as the impression of the most proximal pad of dIII; no proximal pad impression occurs; the anterior triangle has a low $\mathrm{L} / \mathrm{W}$ ratio $(\sim 0.40)$; lack of hallux impressions. Trackway narrow, pes rotation minimal. The preservation grade of the tracks and trackways (e.g., Marchetti et al. 2019) is 1.5 .

Discussion. As noted before Marty et al. (2018) and Belvedere et al. (2019) compared Jurabrontes with M. teutonicus and noted a great overall similarity in the blunt, sometimes sharp, massive digit, clear claw marks, and the rounded heel; the characteristic phalangeal pad pIII1 impression is not visible. The overall shape including L/W ratio is very similar, especially to the less well-preserved Jurabrontes specimens (e.g., Marty et al. 2018: fig. 6e-h). We therefore attribute the Barkhausen theropod footprints to Jurabrontes teutonicus comb. nov. As a general rule, we note that the larger theropod tracks $(L>40 \mathrm{~cm})$ often have a "fleshy appearance and lack well-defined creases separating the digital pads" (Lockley 2000a, b), as also recently confirmed by Lallensack et al. (2019).

Based on skeletal data, Farlow (2018: 100) stated that "across theropods as a group, there is a tendency for digits (especially II and III) to become relatively stouter with increasing size". We agree with Lallensack et al. (2015) that the tridactyl tracks from the Late Jurassic of the Langenberg quarry (near Oker) are very similar to those found in Barkhausen.

The Barkhausen tracks are similar in the overall shape to Iberosauripus grandis Cobos et al. (2014); however, the latter exhibits generally narrower interdigital angles. They differ from Eubrontes giganteus Hitchcock in their smaller size and less-elongated digits, missing phalangeal pad impressions (less-pronounced interdigital pad creases), a lower mesaxony (sensu Lockley 2009), and more pronounced rounded heel pad. If compared to the amended M. uzbekistanicus Gabuniya and Kurbatov (1982), the German tracks have a less sigmoidal digit III, broader and more robust digit impressions and almost completely lacks discrete phalangeal pad impressions; they exhibit a higher symmetry of the III^II and III^IV interdigital angles. Megalosauripus transjuranicus Razzolini et al. (2017) is more elongate and shows clearer phalangeal pad impressions. Most notably, the ichnotaxon exhibits a very characteristic PIV1 phalangeal pad impression (heel pad) that is the widest and largest phalangeal pad with a rounded shape, connected to the rest of the PIV1 impression which is lacking or obscure in Barkhausen footprints. Euthynichnium lusitanicum Nopcsa, 1923 differs in the presence of a hallux impression, allying it to Lessertiseur's concept of Megalosauropis (with an 'i'). Euthynichnium also has higher symmetry, a shorter extension of dIII, and the general shape of the heel region.

Boutakioutichnium atlasicus Nouri et al. (2011) has a marked proximolaterally oriented hallux impression, lacking in most large Late Jurassic theropod tracks and shows a weaker mesaxony. Megalosauropus broomensis Colbert and Merrilees (1967) has an atypical phalangeal pad formula of 3-4-5 for digits II-III-IV (Romilio and Salisbury 2011; Salisbury et al. 2016), which is not visible in the Barkhausen tracks. The apparent differences between Megalosauropus broomfieldensis spelled with an 'o' and Megalosauripus of Lessertiseur spelled with an ' $i$ ' which he compared with Late Jurassic as well as Early Cretaceous tracks generated much discussion and led to the use of the latter ichnogenus (with an ' $i$ ') in new combination for Late Jurassic theropod tracks from North America, Asia, and Europe (Lockley and Meyer 1998), and was recently followed in naming Megalosauripus transjurassicus Razzolini et al. (2017). Bueckeburgichnus maximus Kuhn (1958) (see Lockley 2000a; Megalosauripus sensu Thulborn 2001) differs from the Barkhausen tracks in the extension of dIII (more pronounced mesaxony), a different configuration of the interdigital angles, and the presence of the large and long, posteriorly oriented hallux. Hispanosauropus hauboldi Mensink and Mertmann 1984 (revised and discussed in Lockley et al. 2007; Avanzini et al. 2011 and Foster 2015) has a less sigmoidal dIII, slightly more defined digits, and a more rounded heel region. The ichnotaxon Irenesauripus Sternberg (1932) exhibits wider and blunter digits. Irenichnites Sternberg (1932) shows blunter digits, the occurrence of a heel pad and the dII impression is not separated from the other digits. Tyrannosauripus pilmorei Lockley and Hunt (1994) has a welldeveloped hallux, shows a less-pronounced asymmetry, and has a different overall shape. Bellatoripes fredlundi McCrea et al. (2014) exhibits claw marks and some phalangeal pads and shows a different relative size of digit dII and dIII. The occurrence of clear claw marks, the relatively narrow and slightly asymmetric interdigital angles, and the difference in length of digits II and IV impressions allow us to exclude valid ornithopod ichnotaxa (Díaz-Martínez et al. 2015) from the comparison. 


\section{Conclusions}

The Barkhausen dinosaur tracksite reveals trackway segments attributable to at least nine sauropods heading north, not south as originally proposed. This may indicate gregarious behavior. True tracks are generally significantly smaller than was originally reported.

A revised description of the sauropod tracks, originally named Elephantopoides barkhausensis, identifies the trackmaker as a small/manus, wide gauge variety, similar to at least other unnamed varieties known from the Late Jurassic of Portugal and Utah belonging to the small ichnogenus Parabrontopodus. Such forms may be distinct from small manus, narrow gauge types, and may be due to locomotion and substrate variability. The original manus size must have been somewhat larger in relation to pes size, as many of the manus impressions were reduced in size by the forward displacement of the substrate during the registration of the pes (Fig. 7). Thus, we recognize the Barkhausen and Langenberg tracks as Parabrontopodus barkhausensis comb. nov.

Since the discovery of the Barkhausen site, almost hundred years ago more than 50 tracksites with sauropod footprints have been reported from the Late Jurassic of Portugal, Spain, France, and Switzerland. Most of them were attributed to two different ichnotaxa. Brontopodus and Parabrontopodus were separated on the basis of trackway gauge and the heteropody ratio (Farlow 1992; Lockley et al. 1994c). However, while this general trend remains important, it has been demonstrated that sauropods trackway gauge may sometimes vary from narrow to wide within a single trackway. Examples from the Late Jurassic of Switzerland and the Late Cretaceous of Bolivia (Meyer et al. 2018, 2021) cast doubt on whether the two sauropod ichnotaxa can be separated by gauge variability alone. A revision of the known sauropod trackways would be helpful to address these concerns.

There are two theropod trackways (cf. Lockley and Meyer 2000). The inference that the most deeply impressed of these trackways represents a predator stalking or chasing one of the sauropods is not tenable, as both of the trackways go in opposite directions.
The palaeoenvironment shows hyposaline-to-hypersaline periods (Gramann et al. 1997) and the Barkhausen site most likely represents an ancient tidal influenced delta system. This is corroborated by the palaeobotanical record that points at a fluvial dominated delta plain with a conifer vegetation associated with horsetail carpets along the riverbanks (Schultka 1991).

Advances in the study and ichnotaxonomic refinement of Late Jurassic theropod tracks in Europe allow us to reassess the theropod tracks to the similar well-defined ichnogenus Jurabrontes. Thus, we recognize the Barkhausen and Langenberg tracks as Jurabrontes teutonicus comb. nov. This expands the known occurrences of this ichnogenus and the large apex predator it represents beyond Switzerland, Portugal to Germany, implying a trans-European or even trans-Tethyan distribution (Belvedere et al. 2019). The widespread distribution during the acanthicum/mutabilis zone of the Late Kimmeridgian, the presence of a diverse sauropod ichnoassemblage and a diverse dinosaur skeletal assemblage (Europasaurus, Amanzia, stegosaurs, theropods) corroborates the hypothesis of a 'faunal exchange corridor' between the Rhenish Massif-London-Brabant Massif, the Jura mountains and further south (Massif Central-Iberian Meseta) (Fig. 11; Meyer et al. 2006; Meyer 2011; Razzolini et al. 2017) and most likely also with Gondwana (Belvedere et al. 2019) during sea level low stands. Furthermore, we note a similar widespread occurrence of the ichnotaxon Megalosauripus transjuranicus (Razzolini et al. 2017) representing a medium-sized theropod and the presence of isolated bones attributable to megalosauroids, tetanurans, ceratosaurians, and allosauroids from the Langenberg quarry (Evers and Wings 2020). Gerke and Wings (2016) suggested a faunal exchange via land-connections in the Late Jurassic between Germany, Portugal, and North America because of the similarity of the Northern German theropods. This and the evidence presented above strongly question the presence of persisting island faunas in the Late Jurassic of Europe (contra Sander et al. 2006 and Lallensack et al. 2015). 
Fig. 11 Palaeogeographical map of Europe during the Late Jurassic showing the localities mentioned in the text (combined drawing from data by Lott et al. (2010) and reconstruction from Ron Blakey, Colorado Plateau Geosystems, Arizona, USA deeptimemaps. com). AM Armorican Massif, $B M$ Bohemian Massif, $C M$ Cimbrian Massif, EM Ebro Massif, $F H$ Fennoscandinavian High, $G B$ Grand Bank, $G H$ Grampian High, $H t$ Helvetic and Vocontian through, $I M$ Iberian Meseta, IM Irish Massif, $L B M$ London Brabant Massif, $L G$ Laurentia Greenland, $M C$ Massif Central, $M M$ Moroccan Meseta, $R M$ Rhenish Massif, $P a B$ Paris Basin, $P o B$ Polish Basin, PS Pompeckji Swell, RFH Rinkøbing-Fuenen High, SI Sudetic Island, $W H$ Welsh High

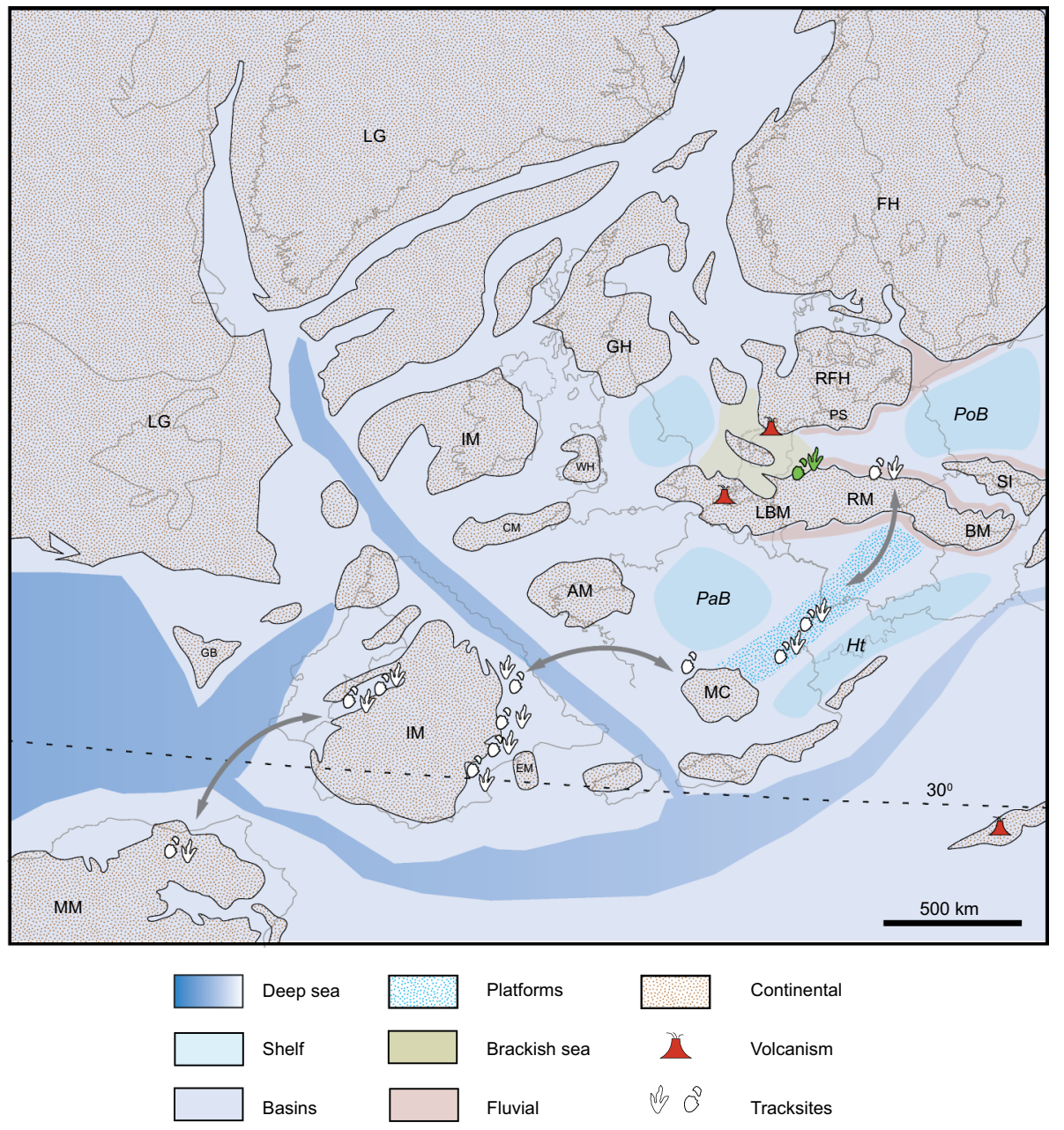

Acknowledgements ML particularly thanks Annette Ludzay and Hartmut Escher. We also received help in the field from Gretchen Minney, Bernd Rosslenbroich, Wolfgang Schad, and Peter Endres. Further logistic support and helpful discussion were provided by the University of Colorado at Denver Dinosaur Trackers Research Group, and Detlev Thies (Hannover). We acknowledge the input and comments of Jim Farlow (USA), Hendrik Klein (Neumarkt/Opf.) and Jan J. Hornung (Hamburg) as reviewers, and Mike Reich (Munich) as editor as well as the help of José Luis Carballido (Trelew) for information on the size of Europasaurus.

Author contributions ML did field work in 1998 and 1999, CAM and BE did field work in 2020, and all three collected the data. CAM, $\mathrm{ML}, \mathrm{MB}$, and $\mathrm{BE}$ provided the description, discussion, and figures, and drafted the manuscript. MB contributed to the manuscript and did the photogrammetric work and some figures. CAM, MB, BE, and ML discussed all parts of the manuscript and contributed to the draft as well as to the revision.

Funding Open Access funding provided by Universität Basel (Universitätsbibliothek Basel). ML was supported by the municipality of Bad Essen for the invitation to study the site and for help with accommodation and transportation. Travel and lodging of the senior author have been funded by the Dinosaurier-Park Münchehagen.

\section{Declarations}

Conflict of interest The authors declare that they have no known competing financial interests or personal relationships that could have appeared to influence the work reported in this paper.

Open Access This article is licensed under a Creative Commons Attribution 4.0 International License, which permits use, sharing, adaptation, distribution and reproduction in any medium or format, as long as you give appropriate credit to the original author(s) and the source, provide a link to the Creative Commons licence, and indicate if changes were made. The images or other third party material in this article are included in the article's Creative Commons licence, unless indicated otherwise in a credit line to the material. If material is not included in the article's Creative Commons licence and your intended use is not permitted by statutory regulation or exceeds the permitted use, you will need to obtain permission directly from the copyright holder. To view a copy of this licence, visit http://creativecommons.org/licenses/by/4.0/. 


\section{References}

Apesteguía, S. 2005. Evolution of the titanosaur metacarpus. In Thunder-Lizards: The Sauropodomorph Dinosaurs, eds. V. Tidwell, and K. Carpenter, 321-345. Bloomington, Ind.: Indiana University Press.

Avanzini, M., P. Laura, and J.G. Garcia-Ramos. 2011. Late Jurassic footprints reveal walking kinematics of theropod dinosaurs. Lethaia 45: 238-252.

Bailly, F., P. Felix-Henningsen, H. Klassen, and S. Stephan. 2000. Synsedimentäre Paläo-Vertisole im Oberjura des westlichen Wiehengebirges. Osnabrücker naturwissenschaftliche Mitteilungen 26: $15-46$.

Ballerstedt, M. 1922a. Über Schreckenssaurier und ihre Fussspuren. Kosmos 19: 77-80.

Ballerstedt, M. 1922b. Zwei grosse, zweizehige Fährten hochbeiniger Bipeden aus dem Wealdensandstein bei Bückeburg. Zeitschrift der Deutschen Geologischen Gesellschaft 73: 76-91.

Barnes, F.A., and M.G. Lockley. 1994. Trackway evidence for social sauropods from the Morrison Formation, Eastern Utah (USA). Gaia 10: 37-42.

Belvedere, M. 2008. Ichnological researches on the Upper Jurassic dinosaur tracks in the Iouaridène area (Demnat, Central HighAtlas, Morocco). Unpublished Ph.D. thesis, Università degli Studi di Padova.

Belvedere, M., D. Marty, K.A. Stevens, S. Ernst, N.L. Razzolini, G. Paratte, M. Cattin, C. Lovis, and C.A. Meyer. 2016. The first unequivocal evidence of gregarious behaviour in baby sauropods (Late Jurassic, NW Switzerland). In Abstract XIV Meeting European Vertebrate Palaeontologists, Harlem, p. 118.

Belvedere, M., D. Castanera, C.A. Meyer, D. Marty, O. Mateus, B.C. Silva, V.F. Santos, and A. Cobos. 2019. Late Jurassic globetrotters compared: A closer look at large and giant theropod tracks of North Africa and Europe. Journal of African Earth Sciences 158: 103547. https://doi.org/10.1016/j.jafrearsci.2019.103547.

Bird, R.T. 1985. Bones for Barnum Brown, 1-225. Fort Worth: Texas Christian University Press.

Carballido, J.L., and M.P. Sander. 2014. Postcranial axial skeleton of Europasaurus holgeri (Dinosauria, Sauropoda) from the Upper Jurassic of Germany: Implications for sauropod ontogeny and phylogenetic relationships of basal Macronaria. Journal of Systematic Palaeontology 12: 335-387.

Carrano, M.T., and J.A. Wilson. 2001. Taxon distributions and the tetrapod track record. Paleobiology 27: 563-581.

Cäsar, S. 2012. Sedimentologie und Sequenzstratigraphie oberjurassischer Karbonate von Norddeutschland (Oxfordium / Kimmeridgium, Niedersächsisches Becken). Unpublished Ph.D. thesis, University of Hamburg, 1-236.

Cobos, A., M.G. Lockley, F. Gascó, R. Royo-Torres, and L. Alcalá. 2014. Megatheropods as apex predators in the typically Jurassic ecosystems of the Villar del Arzobispo Formation (Iberian Range, Spain). Palaeogeography, Palaeoclimatology, Palaeoecology 399: 31-44. https://doi.org/10.1016/j.palaeo.2014.02.008.

Colbert, E.H., and D. Merrilees. 1967. Cretaceous dinosaur footprints from Western Australia. Journal of the Royal Society of Western Australia 50: 21-25.

Diaz-Martinez, I., X. Peredo-Superbiola, F. Pérez-Lorente, and J.I. Canudo. 2015. Ichnotaxonomic review of large ornithopod dinosaur tracks: temporal and geographic implications. PLoS ONE 10: e0115477.

Diedrich, C. 2011. Upper Jurassic tidal flat megatracksites of Germany-coastal dinosaur migration highways between European islands, and a review of the dinosaur footprints. Palaeobiodiversity and Palaeoenvironments 91: 129-155. https://doi.org/ 10.1007/s12549-010-0044-y.
Dutuit, J. M., and A. Ouazzou. 1980. Découverte d'une piste de dinosaure sauropode sur le site d'empreintes de Demnat (HautAtlas Marocain). Mémoire Société Géologique de la France (N. S.) 139: 95-102.

Evers, S.W., and O. Wings. 2020. Late Jurassic theropod dinosaur bones from the Langenberg Quarry (Lower Saxony, Germany) provide evidence for several theropod lineages in the central European archipelago. PeerJ. https://doi.org/10.7717/peerj. 8437.

Falkingham, P.L., K.T. Bates, M. Avanzini, M. Bennett, E.M. Bordy, B.H. Breithaupt, D. Castanera, P. Citton, I. Díaz-Martínez, J.O. Farlow, A.R. Fiorillo, S.M. Gatesy, P. Getty, K.G. Hatala, J.J. Hornung, J.A. Hyatt, H. Klein, J.N. Lallensack, A.J. Martin, D. Marty, N.A. Matthews, C.A. Meyer, J. Milàn, N.J. Minter, N.L. Razzolini, A. Romilio, S.W. Salisbury, L. Sciscio, I. Tanaka, A.L.A. Wiseman, L.D. Xing, and M. Belvedere. 2018. A standard protocol for documenting modern and fossil ichnological data. Palaeontology 61: 469-480. https://doi.org/10.1111/pala.12373.

Farlow, J.O. 1992. Sauropod tracks and trackmakers: integrating the ichnological and skeletal records. Zubia 10: 89-183.

Farlow, J.O. 2018. Noah's Raven. Interpreting the makers of tridactyl dinosaur footprints, 1-634. Bloomington, Ind.: Indiana University Press.

Farlow, J.O., J.G. Pittman, and J.M. Hawthorne. 1989. Brontopodus birdi, Lower Cretaceous sauropod footprints from the U.S. Gulf Coastal Plain. In Dinosaur Tracks and Traces, eds. D.D. Gillette, and M.G. Lockley, 371-394. Cambridge: University Press.

Farlow, J.O., G. O’Brien, G.J. Kuban, B.F. Dattilo, K.T. Bates, P.L. Falkingham, L. Piñuela Suarez, A. Rose, A. Freels, C. Kumagai, C. Libben, J. Smith, and J. Whitcraft. 2012. Dinosaur Tracksites of the Paluxy River Valley (Glen Rose Formation, Lower Cretaceous) Dinosaur Valley State Park, Somervell County, Texas. $V$ Actas de las Jornadas Inernacionales Paleontologia de Dinosaurios y su Entorno, Salas de los Infantes, 41-70.

Fischer, H. 1988. Die Saurierfährten im Naturdenkmal Münchehagen. Mitteilungen aus dem Institut für Geologie und Paläontologie der Universität Hannover 37: 1-25.

Fischer, T., P. Chellouche, M.G. Lockley, and C.A. Meyer. 2021, in press. The Dinosaur Tracks of Bad Essen-Barkhausen in the Unesco Global Geopark TERRA.vita (NW Germany): 100 Years of development from an industrial quarry open-air museum. Geoconservation Research Special Volume.

Foster, J.H. 2015. Theropod Dinosaur Ichnogenus Hispanosauropus identified from the Morrison Formation (Upper Jurassic), Western North America. Ichnos 22: 183-191.

Friese, H. 1972. Die Dinosaurierfährten von Barkhausen im Wiehengebirge. Wittlanger Heimathefte 5: 3-22.

Friese, H. 1979. Die Dinosaurierfährten von Barkhausen im Wiehengebirge. Veröffentlichungen des Landkreises Osnabrück 1: 1-36.

Gabuniya, L.K., and V.V. Kurbatov. 1982 Jurassic Dinosaur Tracks of Tashkurgan (Usbekistan SSR). In Abstracts of the Scientific Session Tiblisi, 20-23.

Gerke, O., and O. Wings. 2016. Multivariate and cladistic analyses of isolated teeth reveal sympatry of theropod dinosaurs in the Late Jurassic of Northern Germany. PLoS ONE 11(7): e0158334. https://doi.org/10.1371/journal.pone.0158334.

Gramann, F., C. Heunisch, H. Klassen, F. Kockel, G. Dulce, F.-J Harms, T. Katschorek, E. Mönning, M. Schudack, U. Schudack, D. Thies, and M. Weiss. 1997. Das Niedersächsische Oberjura-Becken-Ergebnisse interdisziplinärer Zusammenarbeit. Zeitschrift der Deutschen Geologischen Gesellschaft 148 (2): 165-236

Haddoumi, H., A. Charrière, and P.O. Mojon. 2010. Stratigraphy and sedimentology of the Jurassic-Cretaceous continental "Redbeds" of the central High Atlas (Morocco): Paleogeographical 
and geodynamical implications. Geobios 43: 433-451. https:// doi.org/10.1016/j.geobios.2010.01.001.

Haq, B.U., J. Hardenbol, and P.R. Vail. 1987. Chronology of fluctuating sea levels since the Triassic. Science 235: 1156-1167.

Haubold, H. 1971. Ichnia Amphibiorum et Reptiliorum fossilium. Handbuch der Palaeoherpetologie 18: i-viii + 1-123.

Haubold H. 1984. Saurierfährten ( $2^{\text {nd }} e d$.), 1-231. Wittenberg Lutherstadt: A. Ziemsen. (Die Neue Brehm-Bücherei 479).

Haubold, H. 1990a. Die Dinosaurier: System, Evolution, Paläobiologie (4 ${ }^{\text {th }}$ ed.), 1-248. Wittenberg Lutherstadt: A. Ziemsen. (Die Neиe Brehm-Bücherei 432).

Haubold, H. 1990b. Dinosaurs and fluctuating sea lavels during the Mesozoic. Historical Biology 4: 75-106.

Henderson, D.M. 2006. Burly gaits: center of mass, stability, and the trackways of sauropod dinosaurs. Journal of Vertebrate Paleontology 26(4): 907-921.

Hendricks, A. 1981. Die Saurierfährte von Münchehagen bei Rehburg-Loccum (NW-Deutschand). Abhandlungen aus dem Landesmuseum für Naturkunde zu Münster in Westfalen 2: $3-21$.

Jank, M., C.A. Meyer, and A. Wetzel. 2006. Late Oxfordian to Late Kimmeridgian carbonate deposits of NW Switzerland (Swiss Jura): stratigraphical and palaeogeographical implications in the transition area between the Paris Basin and the Tethys. Sedimentary Geology 186: 237-263. https://doi.org/10.1016/j. sedgeo.2005.08.008.

Kaever, M., and A.F. de Lapparent. 1974. Les traces de pas de Dinosaures du Jurassique de Barkhausen (Basse Saxe, Allemagne). Bulletin de la Société Géologique de France S7-XVI: 516-525. https://doi.org/10.2113/gssgfbull.s7-xvi.5.516

Klassen, H. 1968. Zur Frage der Wiehengebirgstransgression. Zeitschrift der Deutschen Geologischen Gesellschaft 117: 144-145.

Klassen, H. 2003. Zur Entwicklungsgeschichte des nördlichen Osnabrücker Berglandes. Osnabrücker Naturwissenschaftliche Mitteilungen 29: 13-43.

Klassen, H. 2006. Zyklotheme in den Oxford- und KimmeridgeAbfolgen des westlichen Niedersachsen-Beckens. Osnabrücker Naturwissenschaftliche Mitteilungen 32: 7-21.

Klüpfel, W. 1931. Stratigraphie der Weserkette. Abhandlungen der Preussischen Geologischen Landesanstalt 129: 423.

Kuhn, O. 1958. Die Fährten der vorzeitlichen Amphibien und Reptilien, 1-64. Bamberg: Meisenbach.

Lallensack, J.N., P.M. Sander, N. Knötschke, and O. Wings. 2015. Dinosaur tracks from the Langenberg quarry (Late Jurassic, Germany) reconstructed with historical photogrammetry: Evidence for large theropods soon after insular dwarfism. Palaeontologica Electronica 18:1-34. https://doi.org/10.26879/529

Lallensack, J.N., T. Engler, and H.J. Barthel. 2019. Shape variability in tridactyl dinosaur footprints: the significance of size and function. Palaeontology 63: 203-228. https://doi.org/10.1111/ pala.12449.

Lallensack, J.N., M. Buchwitz, and A. Romilio. 2020. Photogrammetry in ichnology: 3D model generation, visualisation, and data extraction. EarthArXiv. https://doi.org/10.31223/X5J30D

Lessertisseur, J. 1955. Traces fossiles d'activité animale et leur signication paléobiologique. Mémoire de la Société Géologique de France 74: 1-150.

Lockley, M.G. 2000. Philosophical perspectives on theropod track morphology: blending qualities and quantities in the science of ichnology. Gaia 15: 279-300.

Lockley, M.G. 2000. An amended description of the theropod footprint Bueckeburgichnus maximus Kuhn 1958, and its bearing on the megalosaur tracks debate. Ichnos 7: 217-225.
Lockley, M.G. 2009. New perspectives on morphological variation in tri-dactyl footprints: clues to widespread convergence in develop-mental dynamics. Geological Quarterly 53: 415-432.

Lockley, M.G., and V.F. dos Santos. 1993. A preliminary report on Sauropod trackways from the Avelino Site, Sesimbra Region, Upper Jurassic, Portugal. Gaia 6: 38-42.

Lockley, M.G., and A.P. Hunt. 1994. A track of the giant theropod dinosaur Tyrannosaurus from close to the Cretaceous/Tertiary boundary, northern New Mexico. Ichnos 3: 213-218.

Lockley, M.G., and C.A. Meyer. 1998. Megalosauripus and the problematic concept of Megalosaur footprints. Gaia 337: 313-337.

Lockley, M.G., and C.A. Meyer. 2000. Dinosaur Tracks and Other Fossil Footprints of Europe, i-xviii + 1-323. Chicago: Columbia University Press.

Lockley, M.G., C.A. Meyer, and V.F. dos Santos. 1994. Trackway evidence for a herd of juvenile sauropods from the Late Jurassic of Portugal. Gaia 10: 27-35.

Lockley, M.G., C.A. Meyer, A.P. Hunt, and S.G. Lucas. 1994. The distribution of sauropod tracks and trackmakers. Gaia 10: 223-248.

Lockley, M.G., J.G. Pittman, C.A. Meyer, and V.F. dos Santos. 1994. On the common occurence of manus-dominated sauropod trackways in Mesozoic carbonates. Gaia 10: 119-124.

Lockley, M.G., J.O. Farlow, and C.A. Meyer. 1994. Brontopodus and Parabrontopodus ichnogen. nov. and the Significance of Wideand narrow-gauge Sauropod Trackways. Gaia 10: 135-146.

Lockley, M.G., J.L. Wright, and D. Thies. 2004. Some observations on the dinosaur tracks at Münchehagen (Lower Cretaceous), Germany. Ichnos 11: 261-274. https://doi.org/10.1080/1042094049 0428805.

Lockley, M.G., J. Lires, J.C. García-Ramos, L. Piñuela, and M. Avanzini. 2007. Shrinking the world's largest dinosaur tracks: observations on the ichnotaxonomy of Gigantosauropus asturiensis and Hispanosauropus hauboldi from the Upper Jurassic of Asturias, Spain. Ichnos 14: 247-255.

Lott, G.K., T.E. Wong, M. Dusar, J. Andsbjerg, E. Mönnig, A. Feldman-Olszewska, and R.M.C.H. Verreussel. 2010. Jurassic. In Petroleum geological atlas of the southern permian basin area, ed. J.C. Doornenbal and A.G. Stevenson, 175-193. Houten: EAGE Publications.

Lull, R.S. 1904. Fossil footprints of the Jura-Trias of North America. Memoirs of the Boston Society of Natural History 5: 461-557.

Mallison, H., and O. Wings. 2014. Photogrammetry in paleontology-a practical guide. Journal of Paleontological Techniques 12: 1-31.

Marchetti, L., M. Belvedere, S. Voigt, H. Klein, D. Castanera, I. DíazMartínez, D. Marty, L. Xing, S. Feola, R.N. Melchor, and J.O. Farlow. 2019. Defining the morphological quality of fossil footprints. Problems and principles of preservation in tetrapod ichnology with examples from the Palaeozoic to the present. Earth Science Reviews 193: 109-145. https://doi.org/10.1016/j.earscirev. 2019.04.008.

Marty, D. 2008. Sedimentology, taphonomy, and ichnology of Late Jurassic dinosaur tracks from the Jura carbonate platform (Chevenez-Combe Ronde tracksite, NW Switzerland): insights into the tidal-flat palaeoenvironment and dinosaur diversity, locomotion, and palaeoecology, 1-278. Published Ph.D. thesis, University of Fribourg. (GeoFocus 21).

Marty, D., M. Belvedere, C.A. Meyer, P. Mietto, G. Paratte, C. Lovis, and B. Thüring. 2010. Comparative analysis of Late Jurassic sauropod trackways from the Jura Mountains (NW Switzerland) and the central High Atlas Mountains (Morocco): Implications for sauropod ichnotaxonomy. Historical Biology 22: 109-133. https:// doi.org/10.1080/08912960903503345.

Marty, D., M. Belvedere, N.L. Razzolini, M.G. Lockley, G. Paratte, M. Cattin, C. Lovis, and C.A. Meyer. 2018. The tracks of giant theropods (Jurabrontes curtedulensis ichnogen. \& ichnosp. nov.) 
from the Late Jurassic of NW Switzerland: palaeoecological \& palaeogeographical implications. Historical Biology 30: 928-956. https://doi.org/10.1080/08912963.2017.1324438.

Matthews, N.A., T.A. Noble, and B.H. Breithaupt. 2006. The application of photogrammetry, remote sensing and geographic information systems (GIS) to fossil resource management. Bulletin New Mexico of Natural History \& Science 34: 119-131.

McCrea, R.T., L.G. Buckley, J.O. Farlow, M.G. Lockley, P.J. Currie, N.A. Matthews, and S.G. Pemberton. 2014. A Terror of Tyrannosaurs": the first trackways of Tyrannosaurids and evidence of gregariousness and pathology in Tyrannosauridae. PLOS ONE 9: e103613.

Mensink, H., and D. Mertmann. 1984. Dinosaurier-Fährten (Gigantosauropus asturiensis n.g. n.sp.; Hispanosauropus hauboldi n.g. n.sp.) im Jura Asturiens bei la Griega und Ribadesella (Spanien). Neues Jahrbuch für Geologie und Paläontologie, Monatshefte 1984(7): 405-415.

Meyer, C.A. 1990. Sauropod tracks from the Upper Jurassic Reuchenette Formation (Kimmeridgian; Lommiswil, Kt. Solothurn) of northern Switzerland. Eclogae Geologicae Helvetiae 83: 389-397.

Meyer, C.A. 2011. The hitch-hikers guide to the Late Jurassic and Early Cretaceous-Dinosaur tracks from the Swiss and French Jura Mountains in a sequence stratigraphic context. Dinosaur Track Symposia 2011 Obernkirchen, abstracts volume, p. 25.

Meyer, C.A., B. Thüring, and A. Wetzel. 2006. The hitch-hikers guide to the Late Jurassic-Basement structures pro-vide clues to dinosaur migration routes. Hantkeniana 5: 38.

Meyer, C.A., D. Marty, and M. Belvedere. 2018. Titanosaur trackways from the late Cretaceous El Molino Formation of Bolivia (Cal Orck'o, Sucre). Annales Societatis Geologorum Poloniae 88: 223-241. https://doi.org/10.14241/asgp.2018.014.

Meyer, C.A., D. Marty, and M. Belvedere. 2021. The Late Cretaceous dinosaur track record of Bolivia-review and perspective. Journal of South American Earth Sciences 106: 102992. https://doi.org/ 10.1016/j.jsames.2020.102992.

Nouri, J., I. Díaz-Martínez, and F. Pérez-Lorente. 2011. Tetradactyl footprints of an unknown affinity theropod dinosaur from the upper jurassic of Morocco. PLoS ONE 6(12): e26882. https:// doi.org/10.1371/journal.pone.0026882.

Razzolini, N.L., M. Belvedere, D. Marty, G. Paratte, C. Lovis, M. Cattin, and C.A. Meyer. 2017. Megalosauripus transjuranicus ichnosp. nov., a new Late Jurassic theropod ichnotaxon from NW Switzerland and implications for tridactyl dinosaur ichnology and ichnotaxomy. PLOS ONE 12(7): e0180289. https://doi. org/10.1371/journal.pone.0180289.

Romilio, A., and S.W. Salisbury. 2011. A reassessment of large theropod dinosaur tracks from the mid-Cretaceous (late AlbianCenomanian) Winton Formation of Lark Quarry, central-western Queensland, Australia: a case for mistaken identity. Cretaceous Research 32: 135-142.

Rothe, P. 2014. Lebensspuren im Stein —und die Grundlagen, um sie zu verstehen. In Lebensspuren im Stein. Ausflüge in die Erdgeschichte Mitteleuropas, eds. P. Rothe, V. Storch, and C. von See, 0-17. Weinheim: Wiley-VCH.

Salisbury, S.W., A. Romilio, M.C. Herne, R.T. Tucker, and J.P. Nair. 2016. The dinosaurian ichnofauna of the Lower Cretaceous (Valanginian-Barremian) Broome Sandstone of the Walmadany Area (James Price Point), Dampier Peninsula, Western Australia. Journal of Vertebrate Paleontology 36: 1-152.

Sander, M.P., O. Mateus, T. Laven, and N. Knötschke. 2006. Bone histology indicates insular dwarfism in a new Late Jurassic sauropod dinosaur. Nature 441: 739-741.

Schultka, S. 1991. Beiträge zur oberjurassischen Flora des Wiehengebirges. Geologie und Paläontologie in Westfalen 19: 55-93.

Sternberg, C. 1932. Dinosaur tracks from Peace River British Colombia. Annual Report National Museum Canada, 59-85.

Thies, D. 1998. The dinosaur park Münchenhagen near Hannover (North Germany): education wrapped in entertainment. In $1^{s t}$ International meeting on Dinosaur paleobiology: Museology Program for Portuguese dinosaur tracksites, 105-11. Lisbon.

Thulborn, T. 1990. Dinosaur tracks, i-xvii + 1-410. London: Chapman \& Hall.

Thulborn, T. 2001. History and nomenclature of the theropod dinosaur tracks Bueckeburgichnus and Megalosauripus. Ichnos 8: 207-222.

Wilson, J.A., and M.T. Carrano. 1999. Titanosaurs and the origin of "wide-gauge" trackways: a biomechanical and systematic perspective on sauropod locomotion. Paleobiology 25: 252-267.

Zuo, F., U. Heimhofer, S. Huck, F.W. Luppold, O. Wings, and J. Erbacher. 2018. Sedimentology and depositional sequences of a Kimmeridgian carbonate ramp system, Lower Saxony Basin, Northern Germany. Facies 64: 1. https://doi.org/10.1007/ s10347-017-0513-0. 